\title{
Installation Effects of a Propeller Mounted on a Wing with Coanda Flap. Part II: Numerical Investigation and Experimental Validation
}

\author{
J. Dierke, R.A.D. Akkermans, J.W. Delfs; and R. Ewert ${ }^{\S}$ \\ Institute of Aerodynamics and Flow Technology, Dept. of Technical Acoustics \\ German Aerospace Center (DLR), Lilienthalplatz 7, 38108 Braunschweig, Germany
}

\begin{abstract}
Within the framework of the German project "Bürgernahes Flugzeug" (Citizen Friendly Aircraft), we are investigating the effect of installation on propeller sound. A nine-bladed propeller installed in front of a wing equipped with a Coanda flap is considered. This configuration produces significant high lift and thereby considerably influences the inflow condition of the propeller. The sound generated by the propeller is furthermore shielded by and reflected off the wing. In this contribution, we present an implementation of an acoustic propeller model in a finite differences CAA (computational aeroacoustics) code. Comparisons of isolated propeller computations in a quiescent flow with an analytical model illustrate the correct numerical implementation. The verification of the implementation is presented for an example of an isolated propeller. A comparison for the installed propeller with experiments is conducted for different settings.
\end{abstract}

\section{Introduction}

The collaboration research project BNF ("Bürgernahes Flugzeug") pursues the vision to substantially integrate small regional airports within the European aviation network. To facilitate this, a medium size airplane with short take-off capabilities is needed. Due to several operational factors such as range, speed, passenger capacity, and runway length, a combination of a high-lift wing (utilizing a Coanda flap) and propeller propulsion system is chosen. One of the challenges is the interplay between the growth of the air transportation system and the required reduction of the noise impact.

The sound radiation of an isolated propeller is well understood, starting from the work by Gutin in $1936 .{ }^{1}$ However, the installation of a propulsion system on an aircraft yields either a distortion of the propeller inflow due to upstream flow effects of the wing in a tractor configuration or the impingement of the pylon wake on the rotor in a pusher propeller configuration.

Two kinds of installation effects are distinguished, namely, aerodynamic and aeroacoustic installation effects. Aerodynamic installation refers to effects that cause the propeller to operate in non-uniform flowfield (source effect). The non-uniform flowfield is produced by pylon, wing or fuselage. Aeroacoustic installation denotes the effects resulting from the sound field produced by the propeller propagating through a nonuniform flow field, due to the possible presence of a wing, pylon or fuselage. This latter effect, contrary to the source effect of aerodynamic installation, is solely a propagation effect.

In the past, a mutual increase in propulsion efficiency and a decrease in noise radiation was achieved by increasing the by-pass ratio of turbofan engines. Design based on multiple components becomes more and more elementary, as the increased by-pass ratio results in a stronger coupling between the individual components due to the decreasing clearance of engine and for instance the wing (e.g., the jet-flap interaction

\footnotetext{
*Research scientist, Dept. of Technical Acoustics, AIAA Member.

${ }^{\dagger}$ Research scientist, Dept. of Technical Acoustics, AIAA Member.

¥Professor, Head of Dept. of Technical Acoustics, Senior AIAA Member.

$\S$ Senior scientist, Dept. of Technical Acoustics, Senior AIAA Member.
} 
of UHBR (ultra high bypass ratio) closely mounted to the wing). On the other hand, installation effects can be used beneficially by geometrical shielding of certain radiation directions from the noise source (e.g., partially buried engine intakes).

Within the framework of the German BNF project, we are investigating installation effects on propeller sound. A nine-bladed propeller installed in tractor configuration in front of a high-lift wing (equipped with a Coanda flap) is studied. This high-lift wing considerably influences the inflow condition of the propeller. Figure 1 presents a front view of the complete model in the open test section of the aeroacoustic low-speed wind tunnel (NWB) at DLR. The sound generated by the propeller is considerably influenced by the shield-

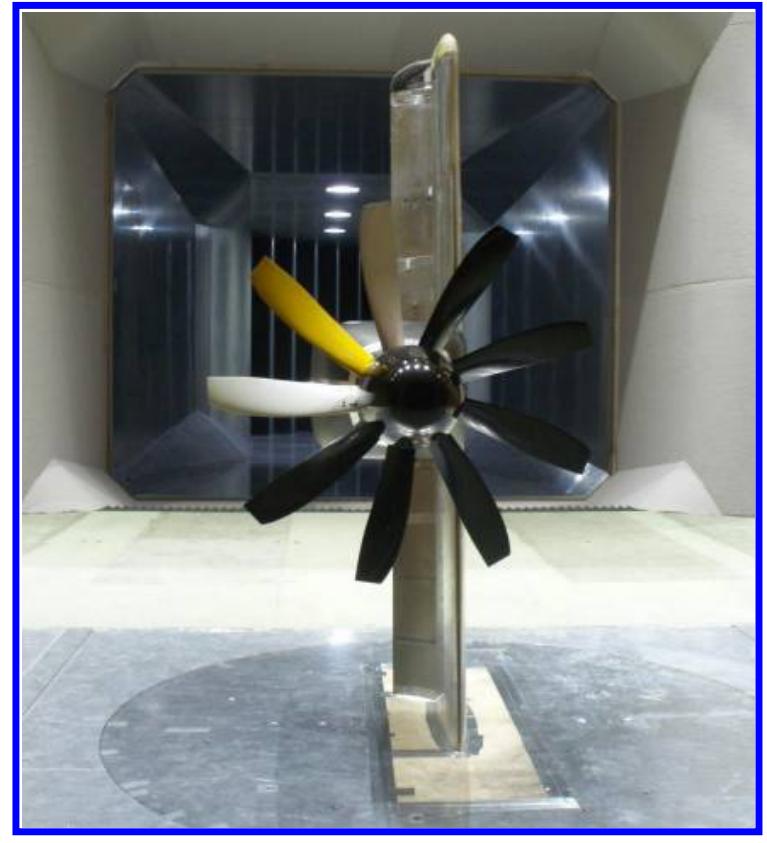

Figure 1. Front view of the BNF-model in the open test section of the aeroacoustic NWB wind tunnel.

ing and reflection of acoustic waves at the wing. To be able to account for all of the complex installation effects for a complete aircraft during design a sufficiently reliable noise prediction is needed. For this reason, the aeroacoustic influence of the engine is modeled and directly coupled into the CAA simulations.

In this paper, we present a novel approach to simulate complex installation effects of a propeller installed in front of a high-lift wing with a CAA method. To facilitate fast computations, the propeller is approximated by an acoustic model that consists of rotating point sources to cover both thickness and loading noise. This approach was successfully applied to Contra Rotating Open Rotors (CROR) (where there is a complex interaction between the two propellers) in frequency domain, coupled with a fast-multipole boundary element method (FM-BEM). ${ }^{3}$ In contrast to the method used by Lummer at al., ${ }^{3}$ the point sources are realized in the finite-differences CAA code PIANO in the time domain enabling also the consideration of inhomogeneous meanflow. This implementation is validated against an analytic solution for simple cases. Furthermore, the computational approach is validated by aeroacoustic experiments in which the propeller is mounted in front of the high-lift wing (see Akkermans et al. ${ }^{2}$ for the detailed description of the aeroacoustic experiments). The modeling enables a fast computation of the aerodynamic as well as aeroacoustic installation effects, while correctly taking into account the non-uniform (background) flow field. Computational results are presented showing that the model covers the noise scaling effect of rotational speed, and blade pitch. Rotating point sources in combination with CAA were also used by Le Garrec and Reboul ${ }^{16}$ for a rear mounted CROR neglecting interaction noise. The researchers have not treated the model in much detail, however it can be guessed that they used a similar approach.

This paper is organized as follows: Following this introduction a description of the methods used to compute the propeller noise is presented in Section II. In Section III test cases for an isolated propeller are compared against the analytic solution to verify the implementation. In section IV the experimental test set-up and the numeric test set-up are outlined. Far field (FF) polar directivities are presented as well as spectra. Finally, in Section V a summary is given and an outlook on further tests is presented. 


\section{Method}

The here presented method is implemented in the finite-difference CAA-code PIANO which is developed to simulate aeroacoustic noise generation and acoustic wave propagation in non-uniform flows in timedomain. The propeller is modeled with appropriate rotating point sources. The resulting acoustic waves are propagated with PIANO, i.e., propagation of the aeroacoustic sound over the underlying background flow and the interaction of this sound with geometry (e.g., a high-lift wing). The propeller model consists of point sources representing each blade by thickness and loading terms. The blade geometry and blade forces are used as input. The underlying mean flow is a RANS or an averaged URANS flow computed with the DLR TAU-code. If necessary, an extrapolation to the far field (FF) is performed by the Ffowcs-Williams \& Hawkings $(\mathrm{FWH})$ code $\mathrm{APSIM}^{+}$in an additional step after the CAA computation. For details of this FWH-code, see e.g., ${ }^{4,5}$ and references therein. The here proposed method consists of three parts:

1. Generating the acoustic sources:

Propeller model

2. Propagation of acoustics over mean background flow (viscous flow from CFD): PIANO

3. Far-field extrapolation with FWH method:

$\mathrm{APSIM}^{+}$

A driving motivation for applying the propeller modeling approach is that it enables a fast computation of the installation effects, both aerodynamic as well as aeroacoustic, while correctly taking into account the non-uniform (background) flow field. Especially during the design phases, a fast and reasonably accurate prediction tool is desired. The propeller model can use input of different quality. Furthermore the mean flow (background flow over which the sound propagates) can be generated with different effort and accuracy. These different ways of obtaining input for the propeller model are illustrated in the schematic presented in Fig. 2 (left). The computational effort to create the mean flow increases from top to bottom in this figure (right). Characteristic of a propeller or rotor are that it emits predominantly tonal noise (which is periodic), and that the occurring frequencies are known beforehand (see, e.g., ${ }^{4}$ ). Therefore we can suffice with a relatively short time signal as input for the FWH method.
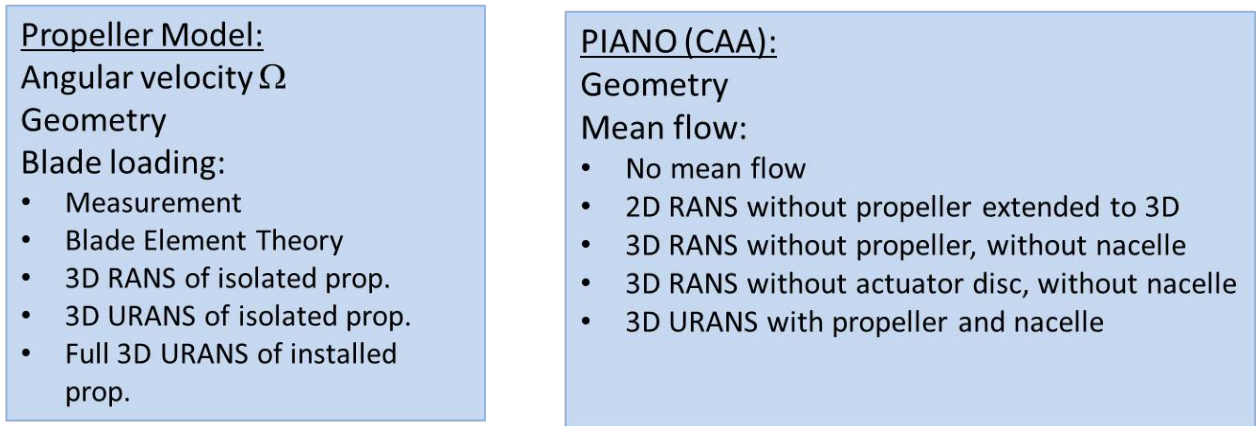

Figure 2. (left) Propeller model input with increasing accuracy and complexness from top to bottom, (right) Input for propagation computation with different accurate mean flows with increasing accuracy and complexness from top to bottom.

\section{A. PIANO}

The acoustic simulations are performed with the DLR CAA-code PIANO on a curvilinear structured multi block mesh. ${ }^{6}$ PIANO can solve linear and non-linear perturbation equations (APE, LEE, and NLDE) over a steady meanflow, usually (but not necessarily) obtained from a RANS simulation. Spatial gradients are approximated using the dispersion relation preserving (DRP) scheme proposed by Tam and Webb. ${ }^{7}$ The temporal discretization is achieved with the 4th-order low-dispersion Runge-Kutta (LDDRK) algorithm proposed by $\mathrm{Hu}$ et al. ${ }^{8}$ In this study, the Linearized Euler Equations (LEE) are used as the governing equation system. As meanflow a RANS solution computed by the unstructured flow solver TAU of DLR was 
used. The LEE with source terms on the right-hand-side (RHS) are given by

$$
\frac{\partial \vec{U}^{\prime}}{\partial t}+\mathbf{A} \frac{\partial \vec{U}^{\prime}}{\partial x}+\mathbf{B} \frac{\partial \vec{U}^{\prime}}{\partial y}+\mathbf{C} \frac{\partial \vec{U}^{\prime}}{\partial z}+\mathbf{M} \vec{U}^{\prime}=\vec{S}
$$

with $\vec{U}^{\prime}=\left(\rho^{\prime}, u^{\prime}, v^{\prime}, w^{\prime}, p^{\prime}\right)^{T}$ and $\vec{S}^{\prime}=\left(S_{1}, S_{2}, S_{3}, S_{4}, S_{5}\right)^{T}$. where $\vec{U}^{\prime}$ represents vector of the perturbation variables. $\mathbf{A}, \mathbf{B}$, and $\mathbf{C}$ are matrices containing terms of mean flow variables, $\mathbf{M}$ is a matrix with terms of mean flow gradients and $\vec{S}$ is the source vector. Quantities with the prime indicate the fluctuating part of the variables. Terms of the propeller model will be used as sources on the RHS of the LEEs $(\vec{S})$. These ring model source terms will be presented in subsection B.

\section{B. Ring model}

The ring model reduces the acoustic contributions of the individual propeller blades to moving point sources located on a certain radius from the rotation center. Two different contributions are considered: loading noise of the propeller blades is modeled by moving point forces on different radii and thickness noise (caused by the propeller blades moving through a fluid with specific density) is reduced to the derivatives of moving masses. From the Ffowcs-Williams and Hawkings wave equation, ${ }^{10}$ analytic expressions be derived for both cases. In frequency domain, they constitute

$$
\begin{aligned}
& \hat{p}_{T m}=-m^{2} B^{3} \Omega^{2} \rho_{0} V_{B} \sum_{j=1}^{N} \hat{G}_{j} e^{-i m B \Phi_{j}} \Delta \Phi \\
& \hat{p}_{L m}=B \sum_{j=1}^{N} \hat{F}_{q}\left(\Phi_{j}\right) \cdot \nabla_{\xi} \hat{G}_{j}\left(\vec{x}_{0} \mid \overrightarrow{x i}_{j}\right) e^{-i m B \Phi_{j}} \Delta \Phi .
\end{aligned}
$$

Subscripts "L" and "T" stand for loading or thickness noise, respectively. Each solution is for the "m"th harmonic of the blade passing frequency (BPF). The number of blades is represented by $B$, rotor rotational speed by $\Omega$, volume of single blade by $V_{B}$, azimuthal position by $\Phi$, and $G$ denotes the Greens function. $N$ is the number of points the ring is approximated with. A shift of $\Delta \Phi=\frac{2 \pi}{B}$ is applied to get the relative position of the other blades. The propeller blade position and the amplitude of the sources are the only information needed in time domain. The position for the $i^{t h}$ blade is given by
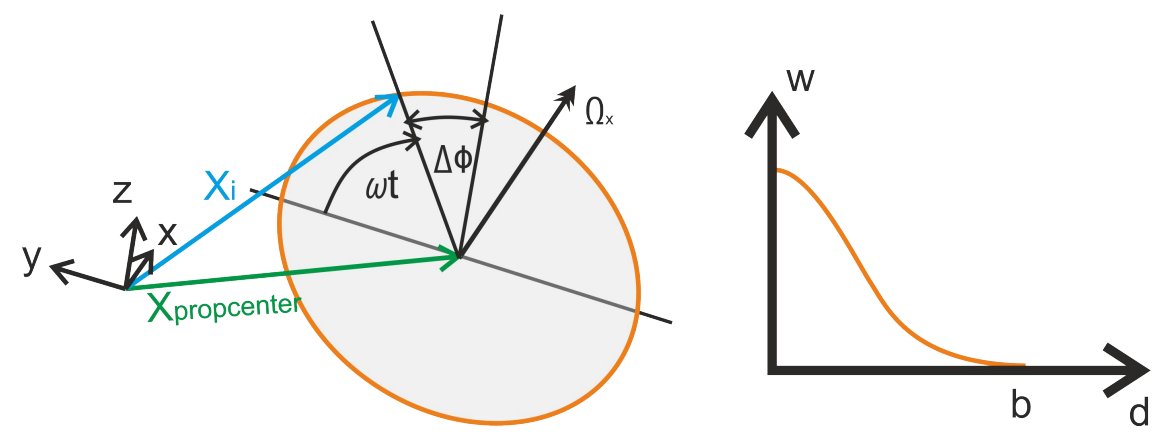

Figure 3. Sketch of ring model for a nine-blade propeller approximated with one ring (left), spatial smoothing function (right).

$$
\vec{x}_{i}=\vec{x}_{\text {propcenter }}+\vec{r}_{i}(t), \text { for } i=1,2, \ldots, B,
$$

with $\vec{x}_{\text {propcenter }}$ denoting the (stationary) center of rotation of the propeller and $\vec{r}_{i}(t)$ the time-dependent relative position. This latter relative position $\vec{r}_{i}(t)$ for an individual blade with the propeller axis parallel to the $\mathrm{x}$-axis is given by

$$
\vec{r}_{i}(t)=r_{\text {ring }}\left[\begin{array}{c}
0 \\
-\sin (\omega t+\Delta \Phi \cdot[i-1]) \\
\cos (\omega t+\Delta \Phi \cdot[i-1])
\end{array}\right],
$$


where $r_{\text {ring }}$ is the radius of the point source ring. Its time derivative is

$$
\overrightarrow{\dot{r}}_{i}(t)=r_{\text {ring }}\left[\begin{array}{c}
0 \\
\omega \cos (\omega t+\Delta \Phi \cdot[i-1]) \\
-\omega \sin (\omega t+\Delta \Phi \cdot[i-1])
\end{array}\right] .
$$

The amplitude for the thickness noise is the volume of the blade $V_{B}$ times the fluids density $\rho_{0}$. The amplitude for the loading noise is simply the negative resulting blade force $-\vec{F}$. The RHS for the Euler equations is the time derivative of the displacement mass, and thus becomes

$$
S_{5}=\frac{\partial}{\partial t}\left[\rho_{0} V_{B} \delta\left(\vec{x}_{i}(t)\right)\right]=\omega r_{r i n g}\left[\rho_{0} V_{B} \delta\left(\vec{x}_{i}(t)\right)\right],
$$

where $\delta$ is the Dirac delta function. The loading sources become

$$
\begin{aligned}
& S_{2}=\left[-F_{x} \delta\left(\vec{x}_{i}(t)\right)\right] \\
& S_{3}=\left[-F_{y} \delta\left(\vec{x}_{i}(t)\right)\right] \\
& S_{4}=\left[-F_{z} \delta\left(\vec{x}_{i}(t)\right)\right] .
\end{aligned}
$$

As a high-order finite-difference code cannot handle real point sources (e.g., a 7-point stencil is used for spatial derivatives), it is necessary to distribute the point sources over a volume. The sources are smoothed using a Gaussian function

$$
w=\frac{1}{(2 \pi)^{3 / 2} \sigma^{3}} \exp \left(-\frac{1}{2} \frac{\left|\vec{x}-\vec{x}_{i}(t)\right|^{2}}{\sigma^{2}}\right)
$$

with $\sigma=1 / 3 b$. The Gaussian is cut off at a distance of $b$ from the point sources, hence it covers $99 \%$ of the distributed quantity.

The complete expression of the distributed thickness noise source term is derived as follows. Starting with the Gaussian distributed mass

$$
m(x, y, z, t)=\rho_{0} V_{B} \frac{1}{\sigma^{3}(2 \pi)^{3 / 2}} \exp \left(-\frac{(x-x(t))^{2}+(y-y(t))^{2}+(z-z(t))^{2}}{2 \sigma^{2}}\right)
$$

we get the time derivate of the mass as

$$
\dot{m}(x, y, z, t)=\rho_{0} V_{B} \frac{1}{\sigma^{5}(2 \pi)^{3 / 2}} \exp \left(-\frac{(x-x(t))^{2}+(y-y(t))^{2}+(z-z(t))^{2}}{2 \sigma^{2}}\right)[(y-y(t)) \dot{y}+(z-z(t)) \dot{z}]
$$

without loss of generality we assume the propeller plane coincide with the $y-z$-plane. The coordinates $x, y, z$ are stationary mesh points, whereas $x(t), y(t), z(t)$ are time dependent blade point positions. The complete Gaussian distributed loading noise source term reads as

$$
\begin{aligned}
& S_{2}=\left[-F_{x} \frac{1}{\sigma^{3}(2 \pi)^{3 / 2}} \exp \left(-\frac{(x-x(t))^{2}+(y-y(t))^{2}+(z-z(t))^{2}}{2 \sigma^{2}}\right)\right] \\
& S_{3}=\left[-F_{y} \frac{1}{\sigma^{3}(2 \pi)^{3 / 2}} \exp \left(-\frac{(x-x(t))^{2}+(y-y(t))^{2}+(z-z(t))^{2}}{2 \sigma^{2}}\right)\right] \\
& S_{4}=\left[-F_{z} \frac{1}{\sigma^{3}(2 \pi)^{3 / 2}} \exp \left(-\frac{(x-x(t))^{2}+(y-y(t))^{2}+(z-z(t))^{2}}{2 \sigma^{2}}\right)\right] .
\end{aligned}
$$

The implementation in a time domain code is rather straight forward. As preprocessing the blocks containing the propeller are marked. Using bounding boxes around the point sources the grid points with RHS are found quickly. The azimuthal depending amplitudes are given as input for 360 points per ring. The necessary steps are as follows:

1. Reading azimuthal depending forces $\left(f_{x}(\Theta), f_{z}(\Theta)\right)$ 
2. Identifying blocks touched by the rings

3. Interpolation of azimuthal depending force on to the CAA points $\left(f_{x}(x, y, z), f_{z}(x, y, z)\right)$

4. Time loop

(a) Computing blade positions

(b) For touched blocks identifying if point $\vec{x}(i, j, k)$ is near a blade source point $\left|\vec{x}(i, j, k)-\vec{x}_{i}(t)\right|<b$

i. Computing source using the smearing function times the azimuth depending force or times $\rho_{0} V_{B}$

(c) Adding the Sources to the RHS of the LEE

During the project the question came up why to use point sources only. The reason was that this simplification is necessary for the ring model in frequency domain. Using force or blade thickness distributions in time domain is as simple as using point sources. In contrast to the point sources a radial dependent volume distribution $V_{B}(r)$ is used and a radial dependent forces $F_{i}(r)$. Instead of the distance to the blade point on a ring the distance $d$ to the blade is used, hence the smoothing function reads $w=\frac{1}{(2 \pi)^{2 / 2} \sigma^{2}} \exp \left(-\frac{1}{2} \frac{d(x, y, z, x(t), y(t), z(t))^{2}}{\sigma^{2}}\right)$. The distance is defined by $d=\mid\left(\vec{x}_{s r c}-\vec{x}(t) \times \vec{e}_{r}(\right.$ blade $) \mid$, with $\vec{x}_{s r c}$ as the propeller center, and $\vec{e}_{r}$ (blade) as the normalized blade direction vector. The Gaussian distributed mass for a known blade volume distribution is

$$
m(x, y, z, t)=\rho_{0} V_{B}(r) \frac{1}{\sigma^{2}(2 \pi)^{2 / 2}} \exp \left(-\frac{d(x, y, z, x(t), y(t), z(t))^{2}}{2 \sigma^{2}}\right)
$$

and the following time derivative reads to

$$
\dot{m}(x, y, z, t)=m(x, y, z, t) \frac{-\pi}{\sigma^{2}} d \dot{d}
$$

\section{Farfield extrapolation (FWH)}

The extrapolation to the farfield is done using the FWH code APSIM ${ }^{+}$. Caused by the huge FWH-surface (including propeller and wing) the signals from different surface positions reach the observer position with a big time shift. Hence a very long sampling time would be needed to get overlapping signals from all surface points at the observer position. Having periodic signals only, with frequencies as modes of the blade passing frequency $(B P F)$, a discrete Fourier transform (DFT) for these frequencies includes the information of the signal for every moment. Using the FWH-integral over the FWH surface with the complex Fourier coefficients for all frequencies provides the Fourier coefficients at the observer position, and hence the sound pressure levels (SPL). This extrapolation method was successfully used even for non-periodic signals for installed CRORs. ${ }^{4,5}$

\section{Verification and plausibiltity tests}

For verification of the implementation simple computations of the isolated propeller are compared against the analytic solution of equation 2. Furthermore, as a plausibility test, the effect of a non-zero Mach number flow on thickness noise is shown. Additionally, the interaction of the blade vortices with a plate are described for a better understanding of the results of the complex experimental installation test case.

\section{A. Set-up of test cases}

The set-up of the test cases is a rectangular CAA-domain consisting of 36 blocks. The extension in $\mathrm{x}-$ direction is from $-1 m$ to $2 \mathrm{~m}$. The $\mathrm{y}$ and $\mathrm{z}$ direction is limited at $-1 \mathrm{~m}$ and $+1 \mathrm{~m}$. Around $4.5 \mathrm{million}$ points resolve acoustic frequencies up to $3 \mathrm{kHz}$ with an acoustic resolution of 7 points per wavelength. The propeller's center lies at the coordinate origin with the x-axis as rotational axis. The FWH-surface encloses the entire propeller. The dimensions of the surface are reduced by $0.1 \mathrm{~m}$ in all directions compared

to the CAA domain outer surface. The data is either presented for a selected microphone or for a line of microphones on a shell. The microphone position is at a distance of $10 \mathrm{~m}$ from the propeller center in the 


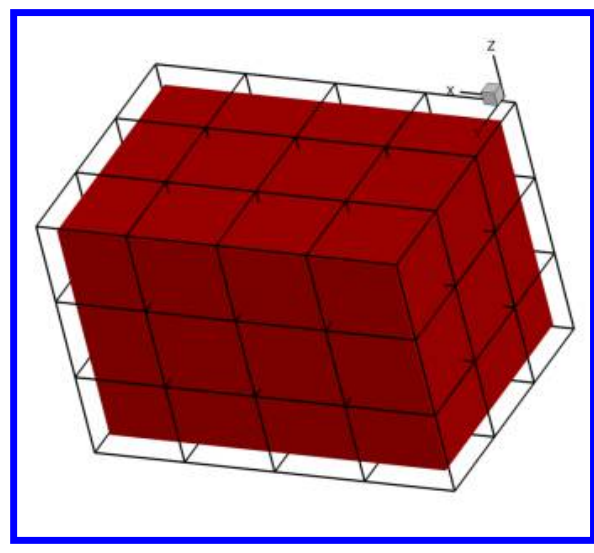

(a) CAA domain and FWH surface in red

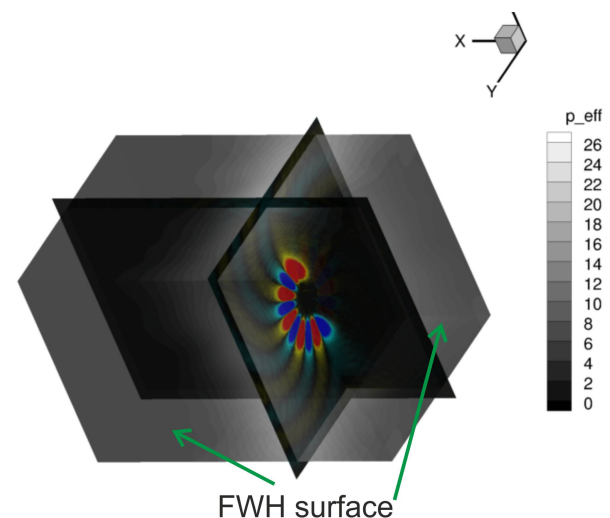

(b) FWH surface showing the effective pressure

Figure 4. Sketches of test case set-up.

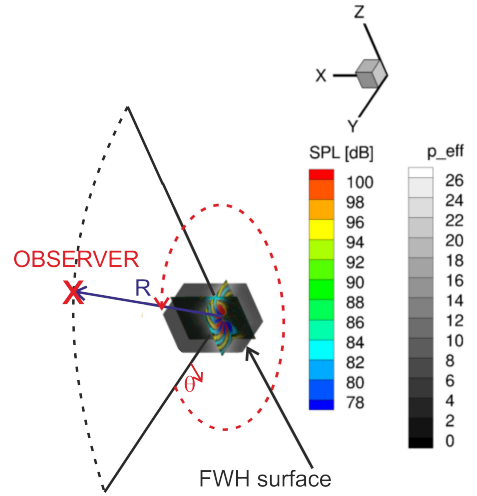

(a) Single microphone position.

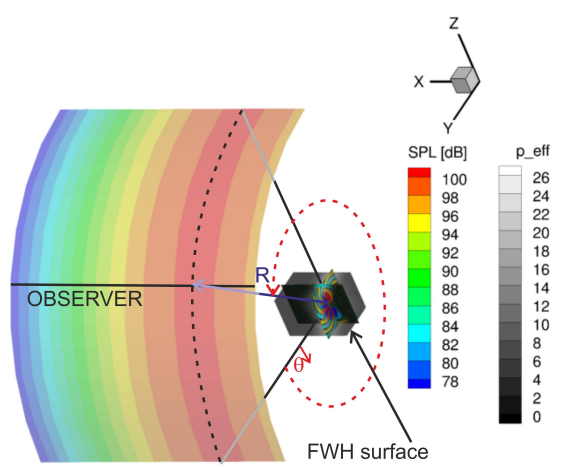

(b) Microphone positions on a shell.

Figure 5. Sketch of test case set-up showing the microphone positions.

propeller plane at $x_{m i c}=(0.0,7.071,7.071)$. This is depicted in Fig. $5(\mathrm{a})$. The observer surface is a shell at a distance of $10 \mathrm{~m}$ from the propeller axis. It covers the positive $y-z$ quadrant and the x-extensions from $-3 m$ to $9 m$ (Fig. 5(b)). The FWH-surface enclosing the propeller is also depicted in this figure showing the effective pressure in grey. The 9 bladed propeller used for the verification tests has a blade volume of $7.2 E-4 \mathrm{~m}^{3}$ each. The propeller diameter is $0.66 \mathrm{~m}$.

\section{B. Verification of thickness noise}

The first test case is an isolated propeller applied with the thickness source contribution $S_{5}$ to verify the implementation. Therefore, thickness noise is computed using the analytic solution (Eq. 2) on the one hand and on the other using CAA including the newly implemented model. The rotational frequency of the propeller is set to $71441 / \mathrm{min}$. The CAA computation uses a source width of $0.12 \mathrm{~m}$. The acoustic pressure snapshots depicted in Fig. 6 show the typical spiral pattern of a propeller and the main radiation direction in the propeller plane. The resulting perturbation field is extrapolated with FWH to the earlier defined microphone in $10 \mathrm{~m}$ distance. Comparison of the CAA simulations with the analytical model yields agreement with respect to the tonal frequencies and the decay behavior for higher harmonics. The CAA prediction is slightly higher than the analytical prediction for the first BPF and around $3 d B$ below for the second BPF. 
(a) Frontal view in yz- (b) Sideview xz-plane plane

Figure 6. Acoustic pressure for thickness noise.

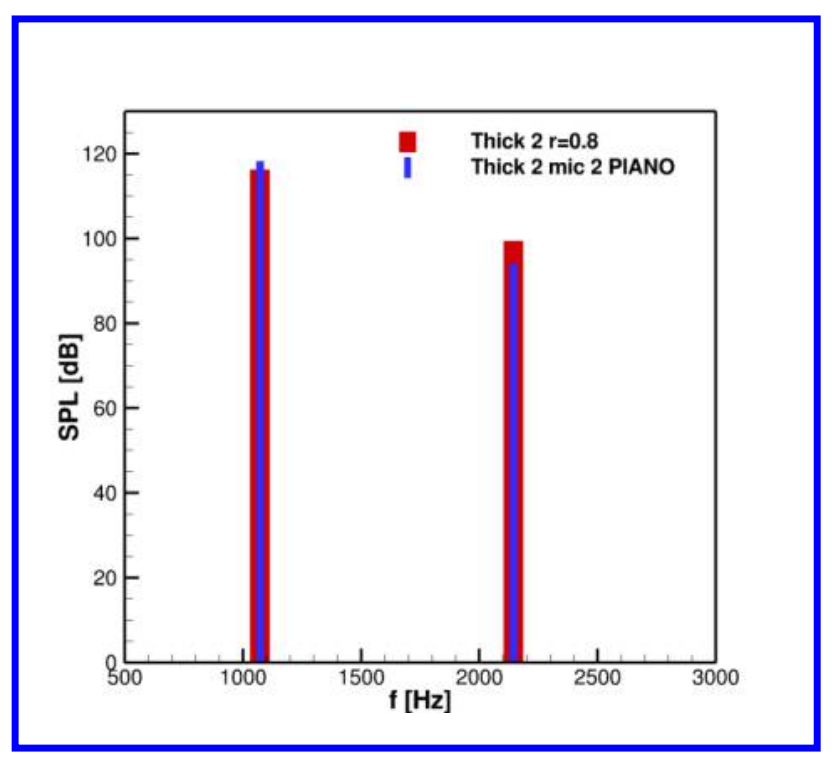

Figure 7. Verification of thickness noise component plotted for the BPFs $1-2$.

\section{Verification loading noise}

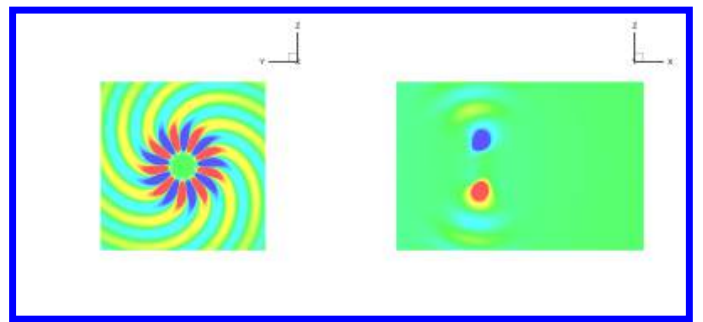

(a) Frontal view in yz- (b) Sideview xz-plane plane

Figure 8. Acoustic pressure for loading noise.

The second test case is again an isolated simple propeller applied with the loading source contribution $S_{2}, S_{3}, S_{4}$. The verification of the loading noise sources is done similarly to the thickness noise verification. Again, the analytic solution is compared against the CAA result. The rotational speed of the propeller is $7144 \mathrm{1} / \mathrm{min}$ and the medium is at rest. The CAA computation uses a source width of $0.12 \mathrm{~m}$. The acoustic pressure snapshots depicted in Fig. 8 again show the typical spiral pattern of a propeller. The main emission direction is slightly shifted out of the propeller plane to the forward direction. The resulting perturbation field is extrapolated with FWH to the earlier defined microphone. The comparison shows an acceptable agreement (Fig. 9(a)). 


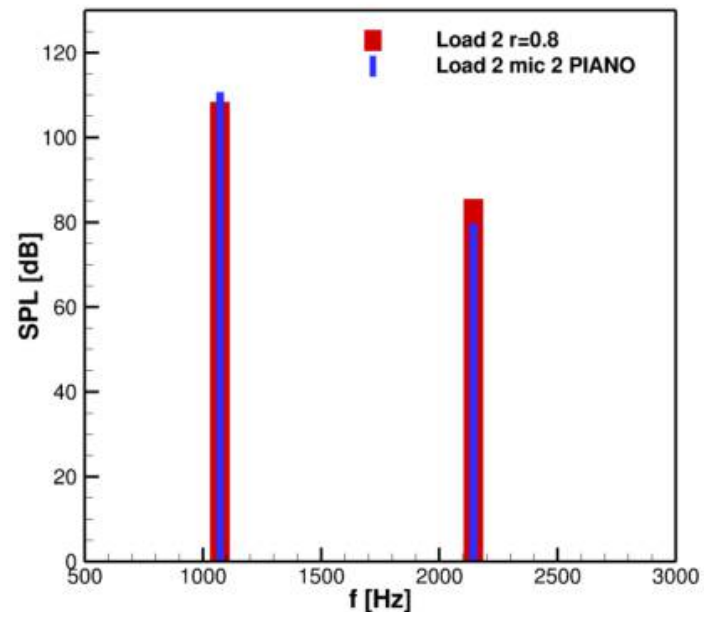

Figure 9. Verification of loading noise component plotted for the BPFs $1-2$.

\section{Mach number effect on thickness noise}

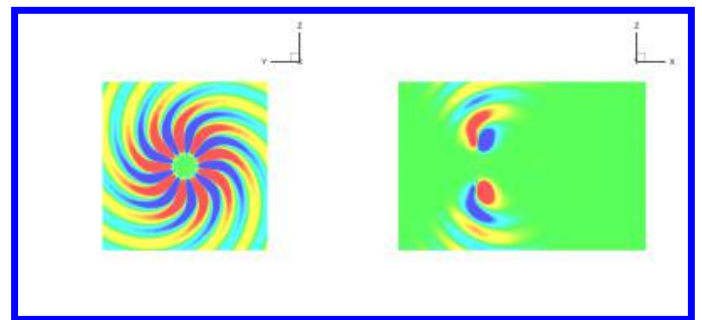

(a) Frontal view in yz- (b) Sideview xz-plane plane

Figure 10. Acoustic pressure for thickness noise at $M a=0.3$.

The main radiation direction of thickness noise for a propeller working in a medium at rest is in the propeller plane. Hanson ${ }^{11}$ showed that the main radiation direction of thickness noise for a propeller in flow is directed slightly more upstream. To verify this effect two computations are evaluated on a line parallel to the propeller axis on the previous described shell $10 \mathrm{~m}$ away from the propeller axis. The propeller's rotational speed is $71441 / \mathrm{min}$ and the Mach numbers are Ma 0.0 and Ma 0.3. The main emission direction is slightly shifted out of the propeller plane to the forward direction (see Fig. 10). The main emission

\begin{tabular}{crrrrrrrrr}
\hline \hline $\begin{array}{r}\text { Test } \\
\text { case }\end{array}$ & Flowtype / Ma & $\begin{array}{r}\Omega \\
{[-]}\end{array}$ & $\begin{array}{r}F_{x} \\
{[1 / \mathrm{min}]}\end{array}$ & $\begin{array}{r}F_{z} \\
{[-]}\end{array}$ & $\begin{array}{r}r_{\text {ring }} \\
{[\mathrm{N}]}\end{array}$ & $\begin{array}{r}\text { T-noise } \\
{[\mathrm{m}]}\end{array}$ & $\begin{array}{r}\text { L-noise } \\
{[-]}\end{array}$ & $\begin{array}{r}\text { No. blades } \\
{[-]}\end{array}$ & {$[-]$} \\
\hline$T 1$ & Const. flow 0.0 & 7144 & $30^{\circ}$ & 0.0 & 0.0 & 0.264 & 1 & 0 & 9 \\
$T 3$ & Const. flow 0.3 & 7144 & $30^{\circ}$ & 0.0 & 0.0 & 0.264 & 1 & 0 & 9 \\
\hline \hline
\end{tabular}

Table 1. Test case parameters for study of Mach number effect on thickness noise. Here, Ma denotes Mach number, $\Omega$ the rotational speed of the propeller, $\beta$ the blade pitch setting, $F_{x}$ the $x$-component of the Thrust, $F_{x}$ the Thrust, $F_{z}$ the propeller drag, $r_{\text {ring }}$ the effective ring radius of the sources, T-noise or L-noise denote the presence (or absence) of Thickness noise or loading noise by the " 1 " (or " 0 ").

direction tilts towards the forward direction, which is the expected behavior. The radiation of the thickness noise at Ma 0.0 is symmetric to the propeller plane. At Ma 0.3 the pattern is shifted to radiation angles around $17^{\circ}$. The curve for the Ma 0.3 case is strongly disturbed for $\mathrm{x}$ greater than 3 . The probable reason is that the sensitive interference pattern is disturbed by small errors $40 \mathrm{~dB}$ below the peak value. 


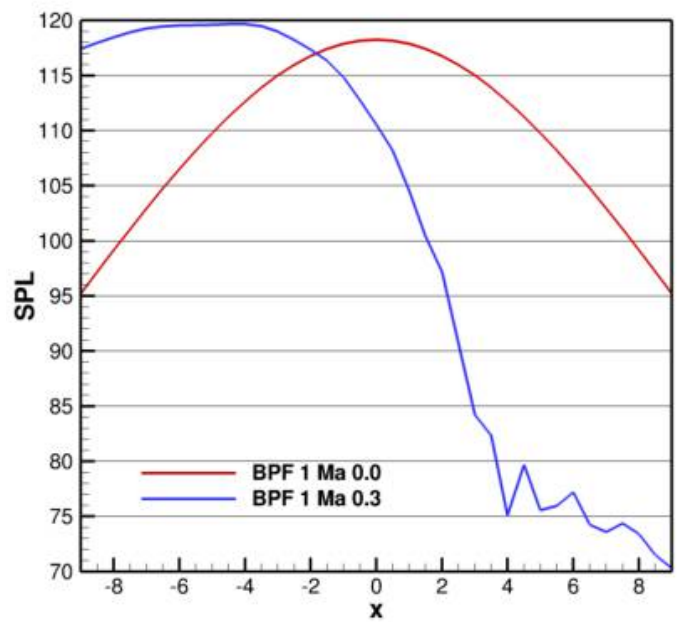

Figure 11. Results for BPF1 on a line in axial direction cutting through the microphone shell.

\section{E. Vortex geometry interaction}

A phenomenon expected for the installed propeller is the sound caused by the interaction of the propeller vortices with the geometry. The code does not dissipate the vortices; therefore an interaction will occur even for a wing far behind the propeller. The effect is demonstrated with a plate positioned behind the

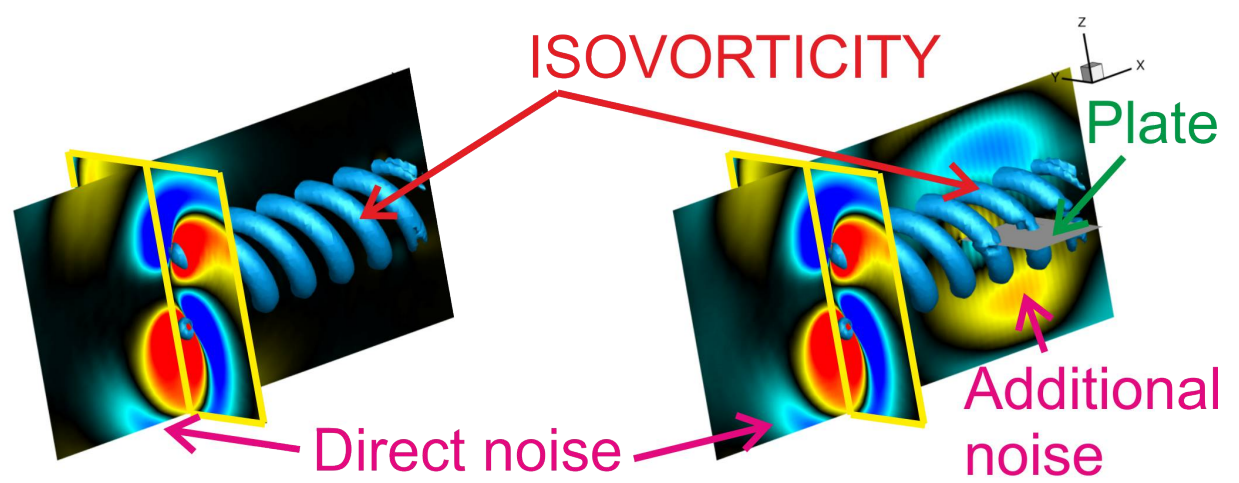

Figure 12. Loading noise without geometry in flow (left) and with flat plate behind the propeller (right); the plate in the propeller wake is an additional sound source.

propeller. In Fig. 12 the reference case without the plate is depicted to the left. The sound wave is directly radiated from the propeller. A different situation is observed with the plate in the propeller wake. It shows the same sound radiated from the propeller, but in addition a pressure pattern is radiated from the plate with opposite signs.

\section{Validation}

To validate the numeric computations for installed propellers, acoustic experiments are conducted in the framework of this project. The wind tunnel model is a one-ninth scale starboard wing with a span of $1.6 \mathrm{~m}$ and a sweep of $10^{\circ}$, it consists of a propeller mounted $0.6 \mathrm{~m}$ in front of a wing which produces a high lift due to the utilization of a Coanda flap. The wing profile is a modified DLR F15 profile, where the flap is rotated by 65 degrees around a point located on the pressure side at $75 \%$ local chord length $c$. At the suction side, a blowing slid is introduced that injects air tangentially to the flap surface at that location. The blowing slid height is set to 6 per mille of the profile thickness. Over the complete spanwise extent, the Coanda flap is present. For a detailed description refer to Akkermans et al. ${ }^{2}$ The propeller is explained by Lenfers in. ${ }^{14}$ 
The experiments took place in NWB's open test section.

\section{A. Experimental set-up}

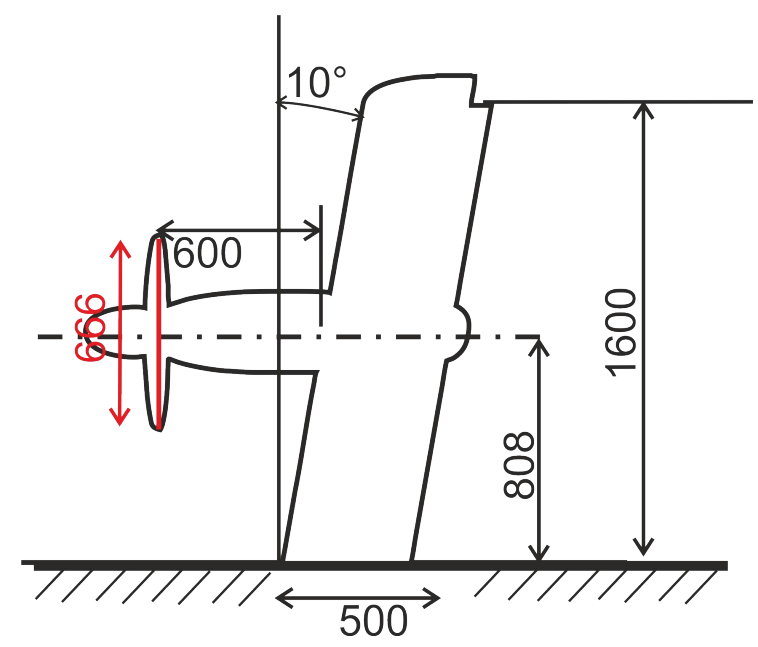

(a) Sketch of the experimental set-up.

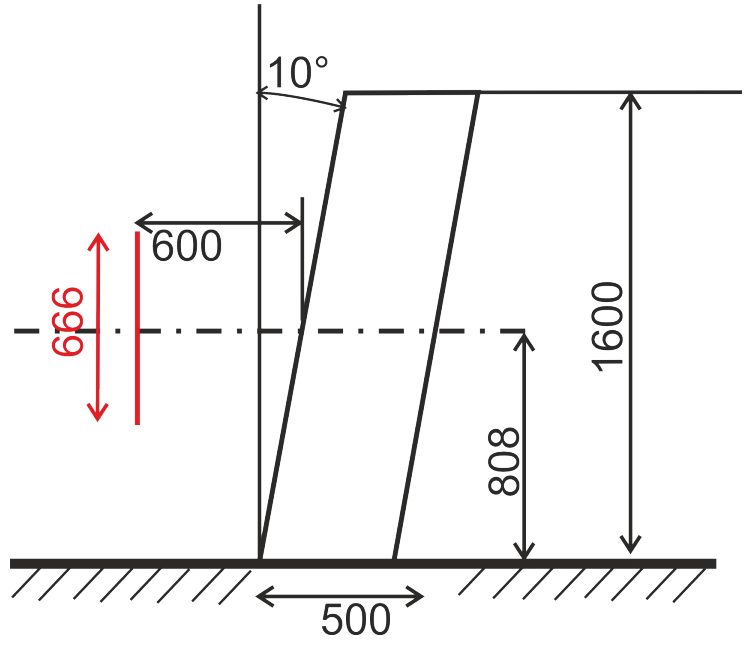

(b) Sketch of the numerical set-up neglecting the nacelle. The red line indicates the position of the propeller.

Figure 13. Sketches of the experimental and numerical set-ups.

The numerical set-up is slightly simplified. The engine and propeller are neglected, as well as the wing's tip. The computational domain ends at the wing tip. The tip was not expected to change the acoustic propagation in a significant way. The coordinate system center of the numeric computations lies at the

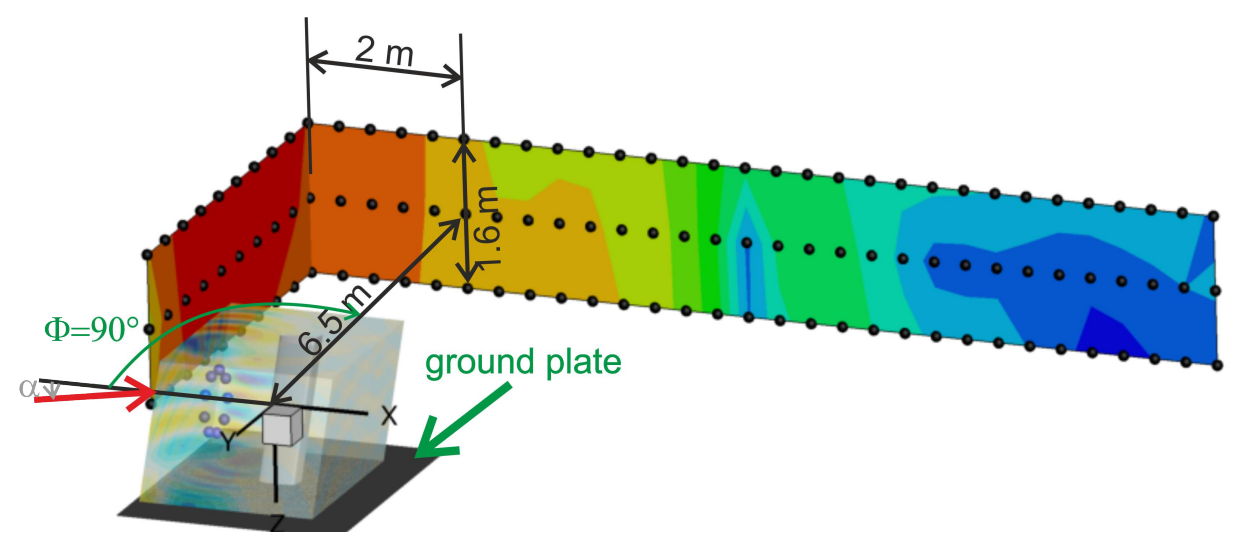

Figure 14. Far-field microphone positions, FWH-surface and ground plate.

wing's nose in the middle of the span. The microphones are positioned in 3 horizontal L-sections. 10 microphones are positioned $2 \mathrm{~m}$ upstream in z-direction. Another 40 microphones are positioned in stream wise direction with constant z-coordinates of $-0.8 \mathrm{~m}, 0.0 \mathrm{~m}$ and $0.8 \mathrm{~m}$. Results shown in this paper used a background flow from a 3D RANS CFD for the isolated wing $\left(M_{\infty}=0.148\right)$. The operating conditions of the engine are as stated in Tab. 2. The CAA domain consists of 288 blocks containing 30 million points. The time step size is $\Delta t=1.45 \cdot 10^{-6} \mathrm{~s}$. The computed number of time steps $T_{\text {steps }}$ is 50000 , which leads to an overall sampling time of $T=0.075 \mathrm{~s}$, hence 8.925 propeller revolutions are computed. A computation takes less than two days on 168 CPUs on DLR's CASE-cluster. The FWH-surface comprises of a box enclosing the complete propeller and high-lift wing. Therefore, both aerodynamic as well as aeroacoustic installation effects are properly accounted for with this prediction chain. To derive the installation effect another set of computations is done without the high-lift wing (in an empty test section). 


\section{B. Results}

Results are shown separated by thickness and loading noise as well as superposed. The thickness noise is computed using point sources whereas the loading noise is computed using point sources or distributed sources. A typical blade loading is depicted in Fig. 34. The effect is shown in Fig. 15 depicting iso-vorticity contours for the loading noise model using point sources (a) and distributed sources (b). A distributed rotating point force results in a vortex pair. This pair is separated into a tip vortex and one at the spinner by extending the point source to a radially distributed one. Three different kinds of plots are presented: directivities, contour plots on the L-shaped far field wall and spectra for a microphone in the propeller plane. To distinguish the installation effect the installed results are compared against those of an empty test section or an empty test section including the ground plate only. Note, that the data is post processed to be comparable with experimental data. Therefore the flow is assumed to be homogeneous of $M a_{\infty}$ outside the FWH surface. Furthermore the data is projected on a sphere with a radius of $1 \mathrm{~m}$ and the center at the wing center.

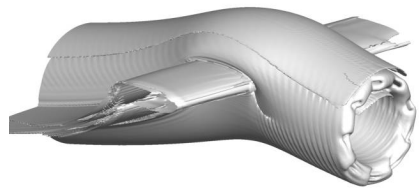

(a) Loading noise (point model)

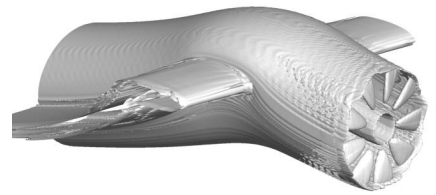

(b) Loading noise (distributed model)

Figure 15. Iso-vorticity contours for loading noise computations.

\section{Directivities}

In Figure 16 the polar directivities for the first two BPFs are depicted for different spanwise coordinates. Subfioure a) shows the inhoard plane directivity $b$ ) the enoine plane directivity and c) the wino tip nlane dire tivity for the installation test case. Noticeable is that the three different planes show directivities with

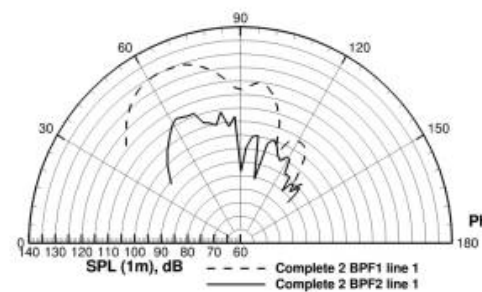

(a) Inboard plane.

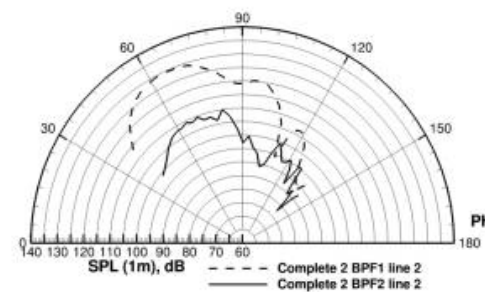

(b) Engine plane.

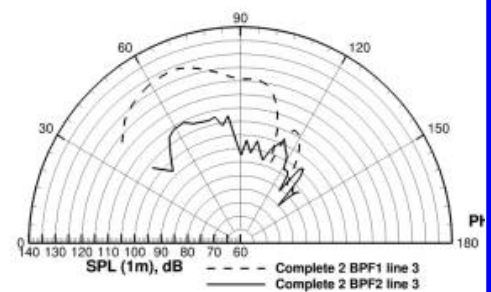

(c) Tip plane.

Figure 16. Directivities for the case $V_{\infty}=51 \mathrm{~m} / \mathrm{s}, \beta=30^{\circ}, \alpha=-5^{\circ}, N_{P}=71441 / \mathrm{min}$.

\begin{tabular}{crrrrrrrrr}
\hline \hline Test & Flowtype / Ma & $\Omega$ & $\beta$ & $F_{x}$ & $F_{z}$ & $r_{\text {ring }}$ & T-noise & L-noise & No. blades \\
case & {$[-]$} & {$[1 / \mathrm{min}]$} & {$[-]$} & {$[\mathrm{N}]$} & {$[\mathrm{N}]$} & {$[\mathrm{m}]$} & {$[-]$} & {$[-]$} & {$[-]$} \\
\hline$C 2$ & Const. flow 0.0 & 7144 & $30^{\circ}$ & -174.0 & -94.0 & 0.264 & 1 & 1 & 9 \\
$C 4$ & Const. flow 0.3 & 5743 & $30^{\circ}$ & -90.0 & -51.6 & 0.264 & 1 & 1 & 9 \\
\hline \hline
\end{tabular}

Table 2. Test case parameters for study of Mach number effect on thickness noise. Here, Ma denotes Mach number, $\Omega$ the rotational speed of the propeller, $\beta$ the blade pitch setting, $F_{x}$ the Thrust, $F_{z}$ the propeller drag, $r_{\text {ring }}$ the effective ring radius of the sources, T-noise or L-noise denote the presence (or absence) of Thickness noise or loading noise by the " 1 " (or "0"). 
completely different patterns for BPF 2. This indicates, that comparisons of exactly the same positions are important to avoid deviations due to the fast spatial changes of the interference pattern. The main radiation direction of BPF 1 for $71441 / \mathrm{min}$ is in $\Phi=60^{\circ}$. A second lobe $10 \mathrm{~dB}$ below is at $\Phi=100^{\circ}$. The last observable lobe is found at $\Phi=120^{\circ} 10-15 d B$ below the second lobe. The lower rotational speed shows the main lobes also in $\Phi=60^{\circ}$ direction for BPF 1 and BPF 2. A second lobe is at $\Phi=110^{\circ}\left(N_{P}=57481 / \mathrm{min}\right.$ case is depicted in the appendix).

\section{Wall microphone data}

In this section the scaled (projected to a sphere with a radius of $1 \mathrm{~m}$ and center at the wing center) sound pressure levels are presented on the wall microphone positions. Each BPF is presented separatly. In Fig. 1719 the data for the thickness noise, the loading noise and the combined thickness and loading noise is shown depicting the case with $N_{P}=71441 / \mathrm{min}$; the case with $N_{P}=57481 / \mathrm{min}$ can be found in the appendix.

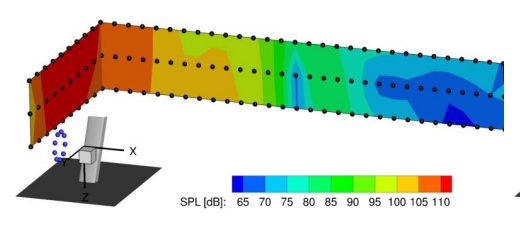

(a) BPF1

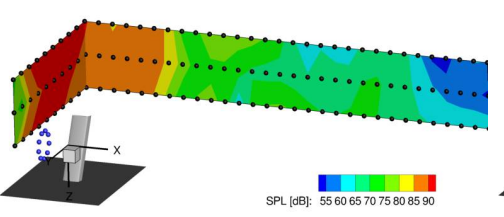

(b) BPF2

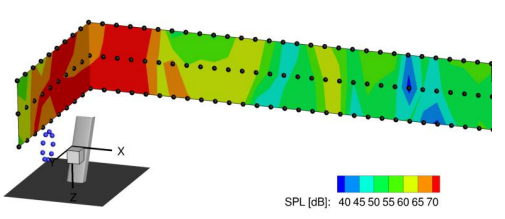

(c) BPF3

Figure 17. Wall microphone data for thickness noise $\left(V_{\infty}=51 \mathrm{~m} / \mathrm{s}, \beta=30^{\circ}, \alpha=-5^{\circ}, N_{P}=71441 / \mathrm{min}\right)$.

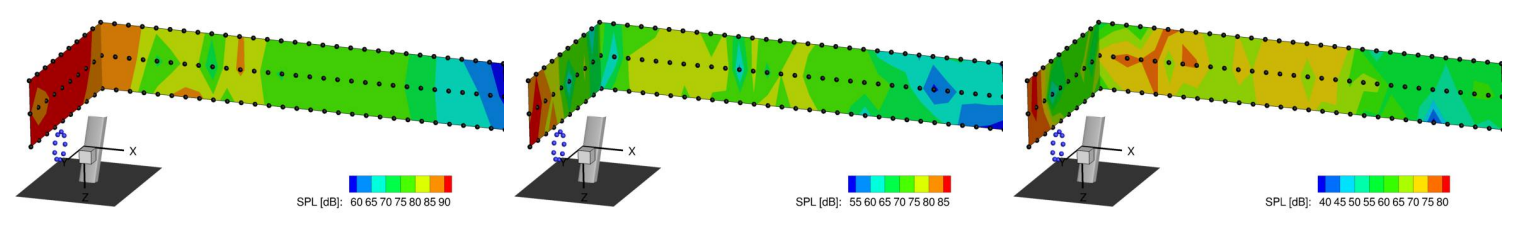
(a) BPF1
(b) BPF2
(c) BPF2

Figure 18. Wall microphone data for loading noise $\left(V_{\infty}=51 \mathrm{~m} / \mathrm{s}, \beta=30^{\circ}, \alpha=-5^{\circ}, N_{P}=71441 / \mathrm{min}\right)$.

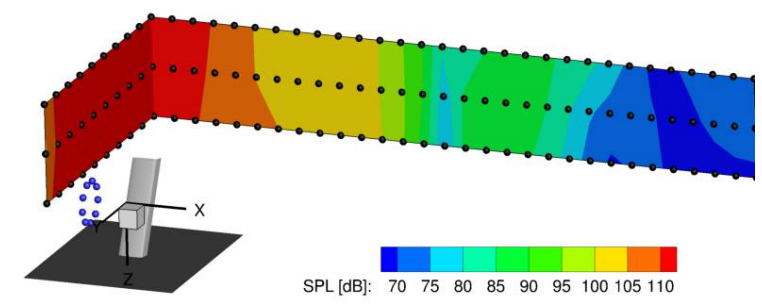

(a) BPF1

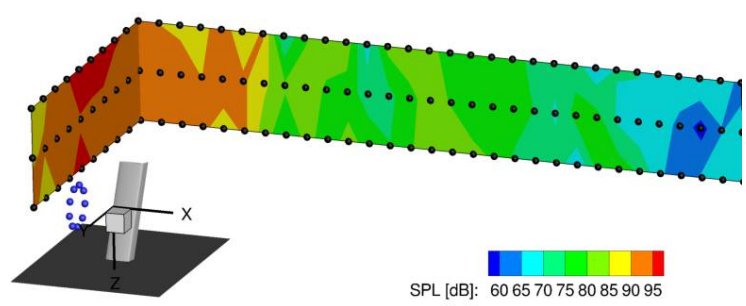

(b) BPF2

Figure 19. Wall microphone $\operatorname{data}\left(V_{\infty}=51 \mathrm{~m} / \mathrm{s}, \beta=30^{\circ}, \alpha=-5^{\circ}, N_{P}=71441 / \mathrm{min}\right)$.

\section{Far field spectra}

The influence of variation of propeller rotational speed is presented in figure 20 for case $V_{\infty}=51 \mathrm{~m} / \mathrm{s}$, $\alpha=-5^{\circ}$ and $\beta=30^{\circ}$. The microphone is $0.15 \mathrm{~m}$ in front of the propeller plane. The rotational speeds are $71441 /$ min and $57431 /$ min. 
Starting with the $71441 / \mathrm{min}$ case the SPL of BPF 1 lies at $123 \mathrm{~dB}$. With increasing BPF the levels decrease by around $15-20 \mathrm{~dB}$. BPF 5 lies higher than the mesh resolution and is therefore ignored. The case with $57431 / \mathrm{min}$ has a different behavior. The overall trend is a decrease of SPL for increased BPF but the decay is much smaller than the higher rotational speed. BPF 2 shows a SPL smaller than for the other BPFs. This unexpected behavior is explained by looking at the spectra for thickness noise and loading noise separatly (Fig. 33). Both spectra show higher levels than the combined spectrum, hence the interference of

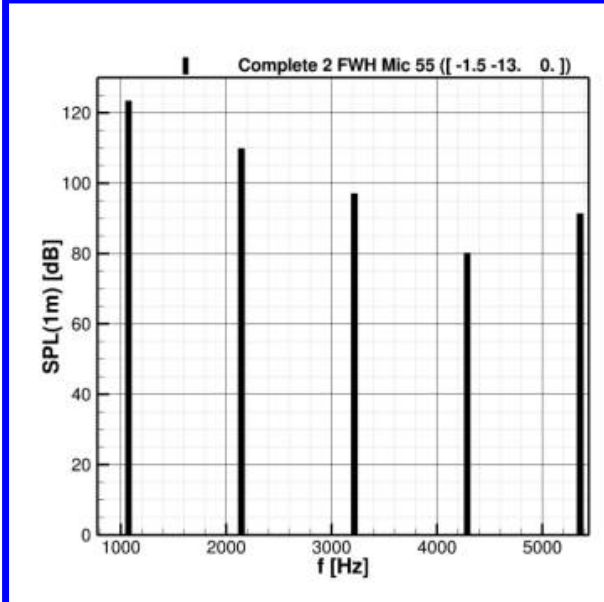

(a) $N_{P}=71441 / \min$

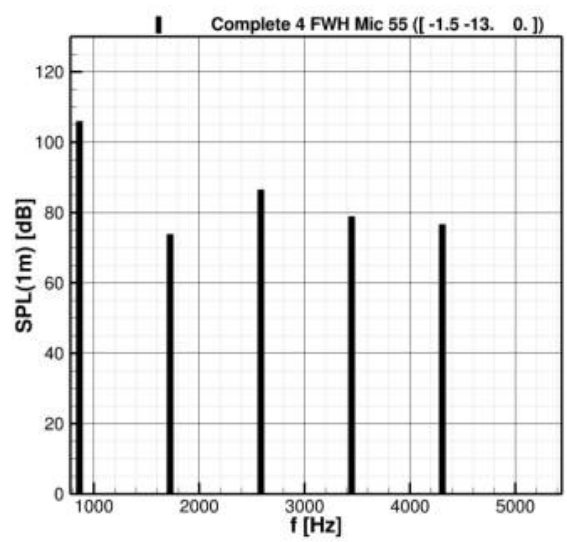

(b) $N_{P}=57431 / \min$

Figure 20. Microphone $0.15 \mathrm{~m}$ in front of the propeller plane $\left(V_{\infty}=51 \mathrm{~m} / \mathrm{s}, \beta=30^{\circ}, \alpha=-5^{\circ}\right)$

the two contributions leads to cancelation of this frequency at this microphone position.

\section{Field data}

The field data give a good impression of where to find the sources and reflections. The first Fig. 21(a) depicts the instantaneous sound pressure for the thickness noise. The typical spiral pattern plus interferences caused by the ground plate reflections and reflections at the high-lift wing is found. In Fig. 21(b) instead of the pressure the instantaneous dilatation $\left(\nabla \cdot \vec{v}^{\prime}\right)$ is plotted, because the pressure exhibits a non-zero mean, making it hard to use for a plot. In addition to the spiral pattern coming from the propeller itself, a circular pattern can be found. Plotting different sets of ellipses potential origins of the waves can be isolated (see Fig. 22). The center of the sound waves marked with the ellipse in (a) is somewhere on the high-lift wing. Due to the sweep it is not possible to mark the definite origin. The second set of ellipses depicted in (b) is related to the flap position. It can be concluded that the installation leads to additional sound sources caused by the propeller vortices interacting with the high-lift wing.

\section{Installation effect}

Isolated propeller results have to be compared with the installed results to get the pure installation effect. Therefore, computations with the isolated propeller are performed. To be able to distinguish between installation effect caused by the ground plate on the one hand and by the high-lift wing on the other hand an additional set of computations is done with propeller and ground plate alone. This kind of set-up is called "semi-installed". The data are presented as directivities of SPL or as differences in SPL. The directivities are evaluated on the mid-plane with $z=$ const. The data is also plotted on the wind tunnel wall in appendix $\mathrm{E}$ to give an overview of the spanwise change of the directivity.

The three cases "isolated", "semi-installed" and "installed" are plotted in Fig. 23 for the first three BPF for thickness noise. Fig. 24 shows the differences between the cases or, in other words, the quantified installation effect of thickness noise. For BPF 1 a minor shift of the lobes to higher angles is observed for the "installed"-case in contrast to the "isolated"-case. The reason could be the circulation around the high-lift wing. The second phenomenon is a more accentuated kink at $\Phi=115^{\circ}$ for the "installed"-case. The opposed phenomenon is found for BPF 2. A kink found for the "isolated" and "semi-installed"-case lies at $\Phi=100^{\circ}$ 


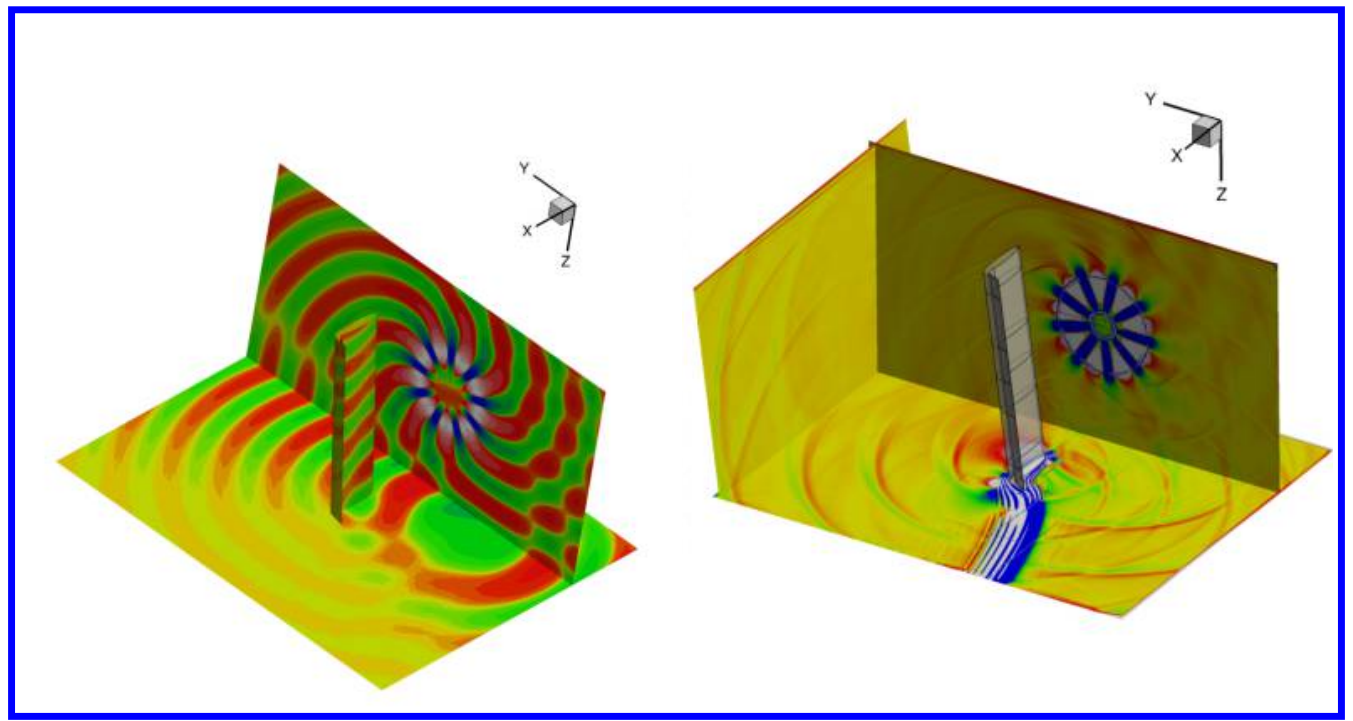

(a) Thickness noise (sound pressure)

(b) Loading noise (dilatation)

Figure 21. Field data $\left(V_{\infty}=51 \mathrm{~m} / \mathrm{s}, \beta=30^{\circ}, \alpha=-5^{\circ}, N_{P}=71441 / \mathrm{min}\right)$

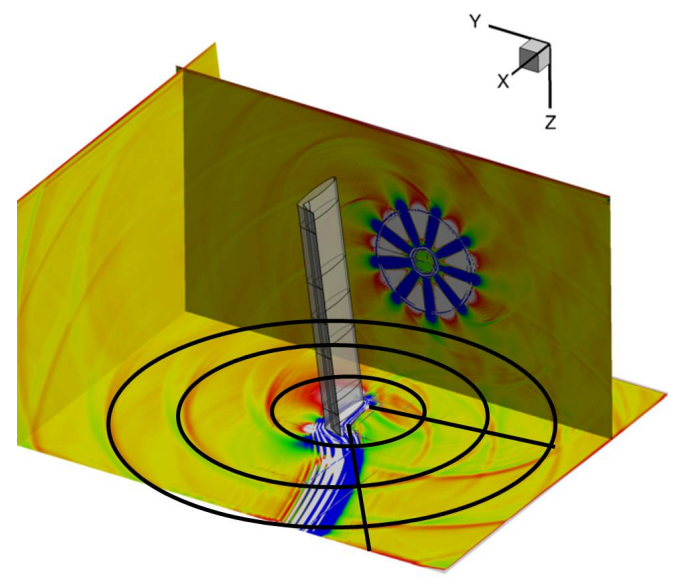

(a) Loading noise (dilatation)

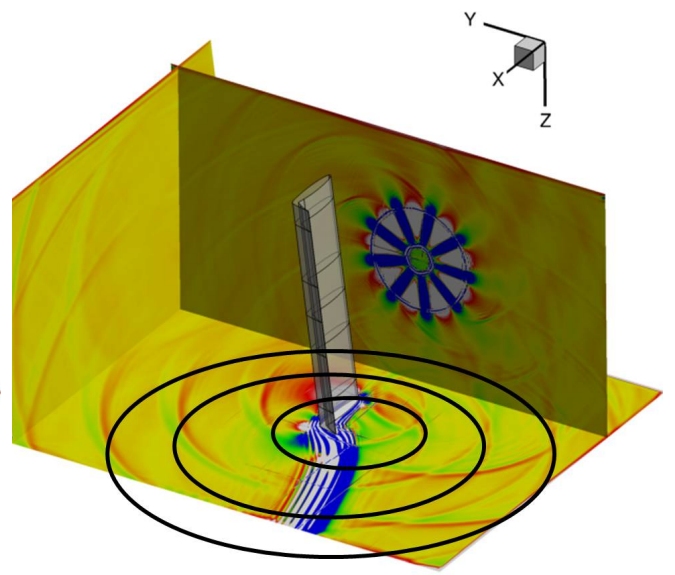

(b) Loading noise (dilatation)

Figure 22. Field data indicating noise origins $\left(V_{\infty}=51 \mathrm{~m} / \mathrm{s}, \beta=30^{\circ}, \alpha=-5^{\circ}, N_{P}=57431 / \mathrm{min}\right)$

and is not found for the "installed"-case. An explanation could be a disturbed cancelation by the wing. BPF 3 does show more wiggles and is therefore hard to interpret.

The installation effect is depicted in Fig. 24 (a) by subtracting the directivity of the "isolated"-case from the "installed"-case. Neglecting the wiggling BPF 3, only minor changes are found in the forward arc with maximum changes of $2 d B$. There are bigger deviations for the backward arc, but strongly localized at locations with the kinks in Fig. 23. Subtracting the "semi-installed"-case from the "installed"-case we get nearly the same results (Fig. 24 (b)), which is confirmed by the comparison of "isolated" and "semiinstalled"-case showing only minor differences in SPL (Fig. 24 (c)). In conclusion there is only a minor influence on thickness noise due to the ground plate. There is a strongly localized installation effect caused by the high-lift wing.

The three cases "isolated", "semi-installed" and "installed" are also plotted in Fig. 25 for the first three 

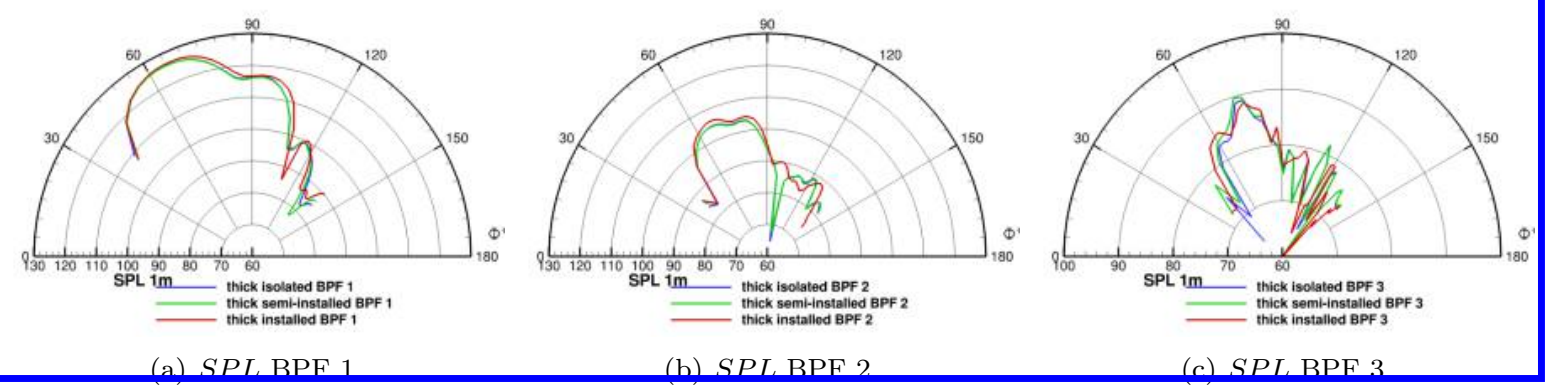

Figure 23. Directivity for isolated, semi-installed and installed case for thickness noise $\left(V_{\infty}=51 \mathrm{~m} / \mathrm{s}, \beta=30^{\circ}\right.$, $\left.\alpha=-5^{\circ}, N_{P}=71441 / \min \right)$.
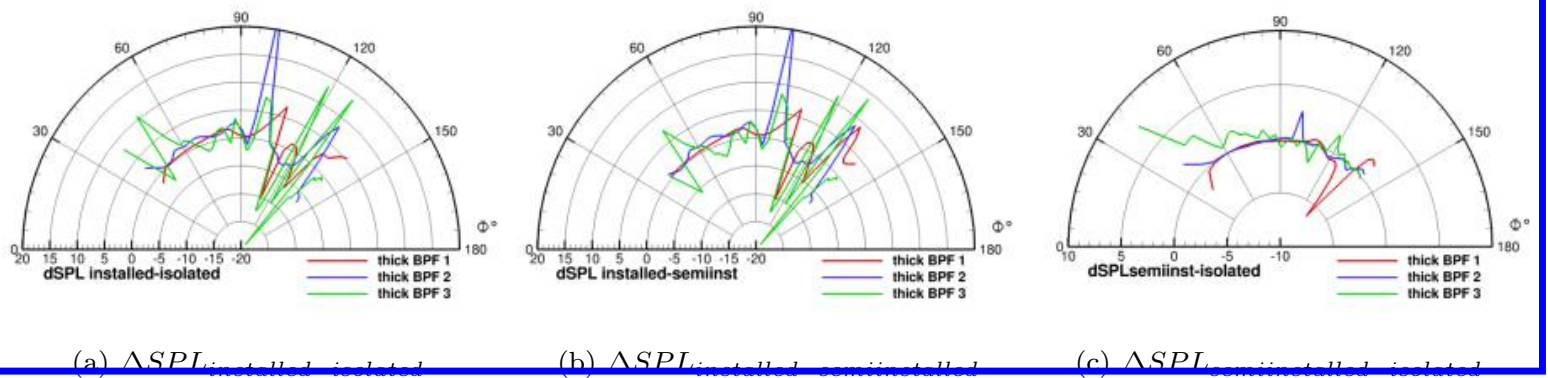

Figure 24. Directivity of installation effects for thickness noise $\left(V_{\infty}=51 \mathrm{~m} / \mathrm{s}, \beta=30^{\circ}, \alpha=-5^{\circ}, N_{P}=71441 / \mathrm{min}\right)$.

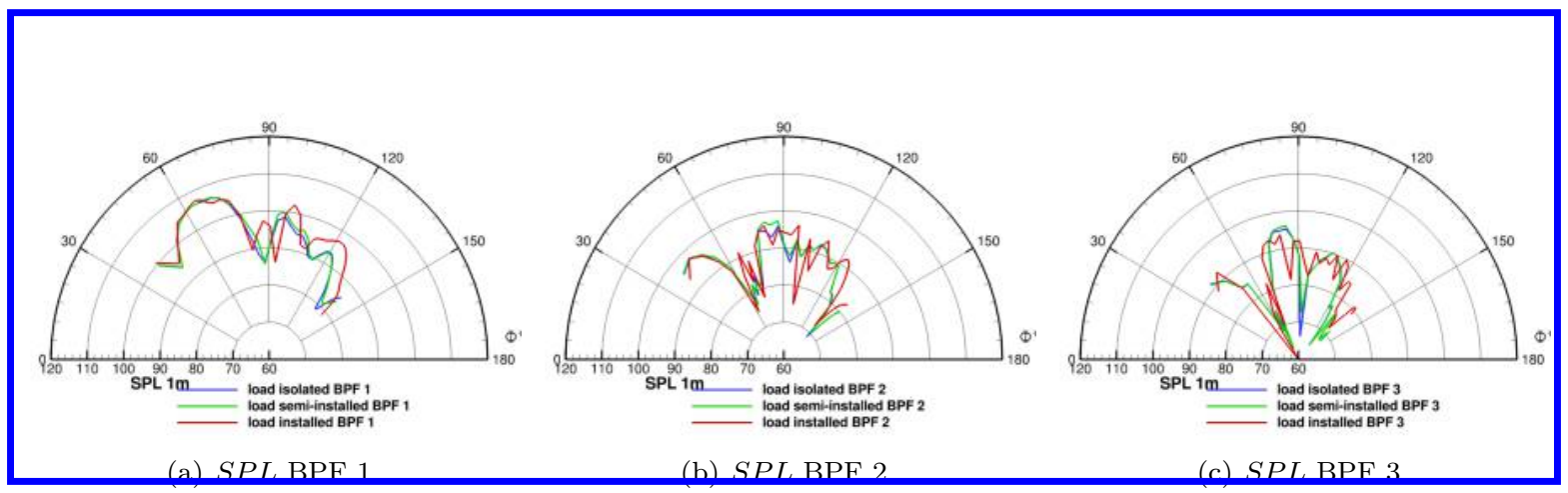

Figure 25. Directivity for isolated, semi-installed and installed case for loading noise $\left(V_{\infty}=51 \mathrm{~m} / \mathrm{s}, \beta=30^{\circ}\right.$, $\left.\alpha=-5^{\circ}, N_{P}=71441 / \min \right)$.

BPF for loading noise. Fig. 26 shows the differences between the cases, the quantified installation effect of loading noise. The directivities of the "isolated" and "semi-installed"-case are nearly equal for the all BPFs. The general pattern of the "installed"-case is the same as for the other cases, but it is more disturbed than the other cases for BPF 2 and 3. Comparing BPF 1 of the "installed"-case with the other cases shows a $5 d B$ higher lobe at $\Phi=120^{\circ}$.

The "installed"-case has more kinks and peaks than the other cases. An explanation could be cancelation and constructive interference due to reflection at the wing or due to an additional sound source of the tip vortices interacting with the geometry.

The installation effect is depicted in Fig. 26(a) by subtracting the directivity of the "isolated"-case from the "installed"-case. BPF 1 shows only minor changes in the forward arc $\left(\Phi<85^{\circ}\right)$ with max. changes of $2 d B$. There are bigger deviations for the backward arc with one kink of $-10 d B$ at $\Phi=95^{\circ}$ and some peaks increasing the level around $5-10 d B$. The other BPFs have a more erratic behavior. Subtracting 
the "semi-installed"-case from the "installed"-case we get nearly the same results (Fig. 26 (b)). This is confirmed by the comparison of the "isolated" and "semi-installed"-case showing only minor differences in levels (Fig. 26 (c)). The conclusion is that there is only a minor influence on the radiated sound due to the ground plate on loading noise. There is an installation effect with an increase of $5-10 d B$ caused by the

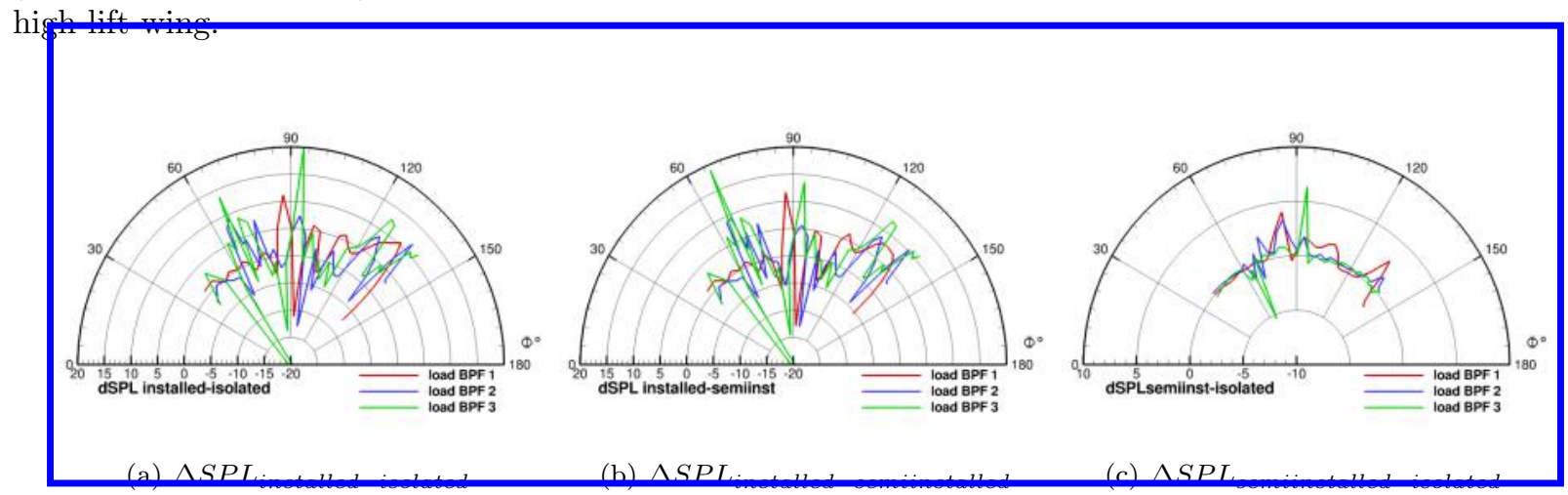

Figure 26. Directivity of installation effects for loading noise $\left(V_{\infty}=51 \mathrm{~m} / \mathrm{s}, \beta=30^{\circ}, \alpha=-5^{\circ}, N_{P}=71441 / \mathrm{min}\right)$.

\section{Comparison with measured data}

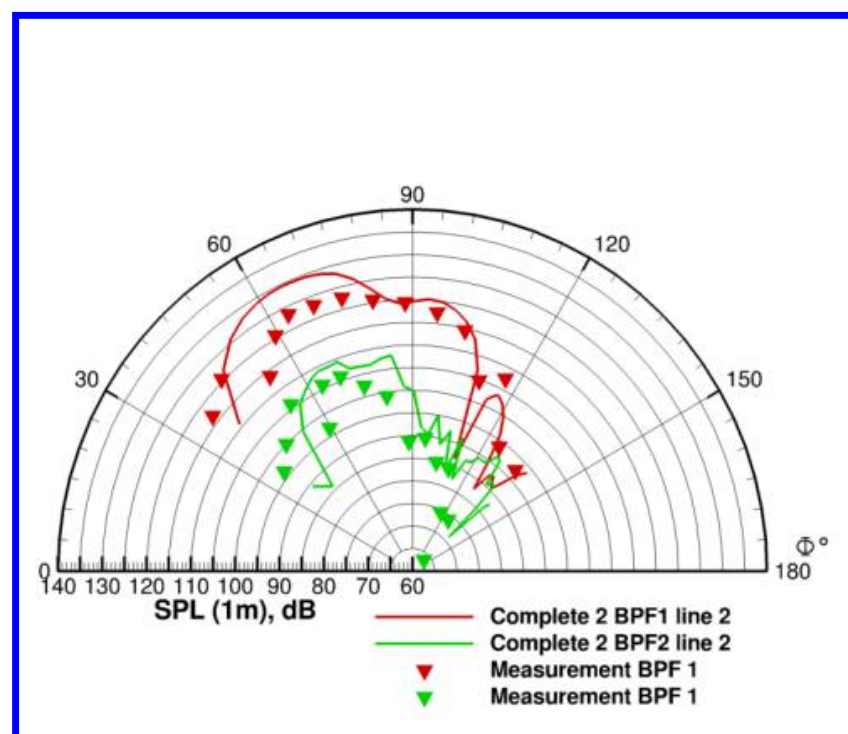

(a) Directivity

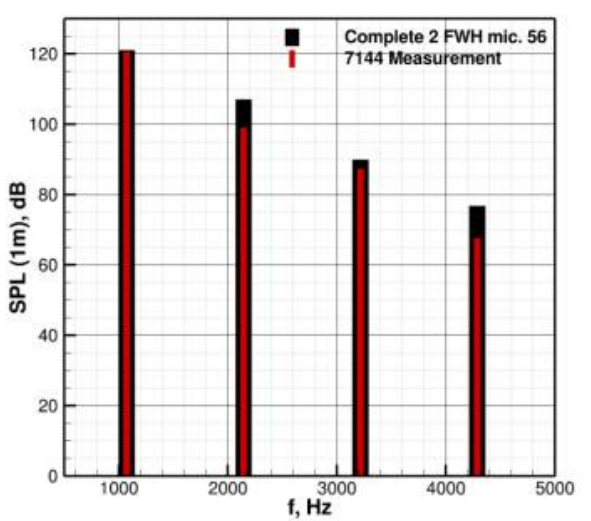

(b) Spectra of BPFs for microphone in propeller plane.

Figure 27. Comparison of measured data with computed data microphone $\left(V_{\infty}=51 \mathrm{~m} / \mathrm{s}, \beta=30^{\circ}, \alpha=-5^{\circ}\right.$, $\left.N_{P}=71441 / \min \right)$

In this subsection a comparison of measured data with our computed data is presented. Amiet's correction is applied to the measured data and it is projected to a sphere with $1 \mathrm{~m}$ radius. The sphere's center lies in the middle of the wing. The computed data is extrapolated with FWH to the far field wall microphones assuming a homogeneous mean flow. Finally the sound pressure levels are also projected to a $1 \mathrm{~m}$ radius sphere. In Fig. 27(a) directivities are plotted for the first two BPFs $\left(V_{\infty}=51 \mathrm{~m} / \mathrm{s}, \beta=30^{\circ}, \alpha=-5^{\circ}\right.$, $\left.N_{P}=71441 / \mathrm{min}\right)$ of measurement and computation. The overall trend of BPF 2 being at least $10 \mathrm{~dB}$ below BPF 1 is found in measurement as well as in the computation. The main emission lobe of BPF 1 is at $65^{\circ}$ for measurement and computation. However, the measurement lies $6 d B$ below the CAA prediction. The second lobe at $95^{\circ}$ shows better agreement within a band of $3 \mathrm{~dB}$. The third lobe at $118^{\circ}$ is slightly 
under predicted. The cut at $115^{\circ}$ is more accentuated by the computation than by the measurement. The predicted main lobe of BPF 2 at $65^{\circ}$ fits the measurement well. In Fig. 27 (b) spectra of the BPFs are compared between measurement and prediction for a microphone in the propeller plane. The trend of the measurement for increasing BPFs is a reduction of around $14 d B$ per BPF. The difference between prediction and measured data for the first BPF is smaller than $1 \mathrm{~dB}$. The second and fourth BPF are under predicted by around $6-7 d B$. The third one is within a range of $2 d B$ around the measurement.

Figure 27(a) depicts the directivities for the first two BPFs for the smaller rotational speed $\left(V_{\infty}=51 \mathrm{~m} / \mathrm{s}\right.$, $\left.\beta=30^{\circ}, \alpha=-5^{\circ}, N_{P}=51051 / \mathrm{min}\right)$. For the forward arc, the measurement shows a lobe $10-15 \mathrm{~dB}$ above the general SPL for BPF 1 at $\Phi=65^{\circ}$. BPF 2 has a $10 d B$ kink instead at the same position. The computation does also have the main lobe at $\Phi=65^{\circ}$ for BPF 1 , but in a wider range of angles. The kink for BPF 2 is missing. However the general SPL is in the right range. The backward arc shows a second lobe of BPF 1 for the measurement as well as for the prediction. The computed SPL lies roughly $10 d B$ below the measured one. In contrast to this underprediction for BPF 1, we get an over prediction of around $8 d B$ for BPF 2. In Fig. 28 (b) spectra of the BPFs are compared between measurement and prediction for a microphone at $\Phi=90^{\circ}$. The trend of the measurement for increasing BPFs is a reduction of around $9 \mathrm{~dB}$ per BPF. The general trend of the computations is the same, however there is a slight underprediction for uneven BPFs of up to $2 d B$ and an over prediction of around $5 d B$ for even BPFs.

The agreement between measurement and computations is quite acceptable. A lot of uncertainties cannot be estimated, like applying Amiet's correction for an extended and non-local sound source. Other uncertainties are the use of the mean flow without the propeller tube as well as the use of propeller data for an isolated propeller without angle of attack. Slight deviations of the microphone positions result in strong differences of the data due to the complex interference patterns, which could also be a reason for differences between CAA and measurements. It is known, that the higher the rotational speed of the rotor is the higher is the weight of the thickness noise in contrast to the loading noise. The better fit of the directivity shape for the higher rotational speed than for the lower one indicates that the thickness noise is reproduced better than the loading noise part. A reason could be that the missing slipstream impacts more on the loading noise than on the thickness noise.

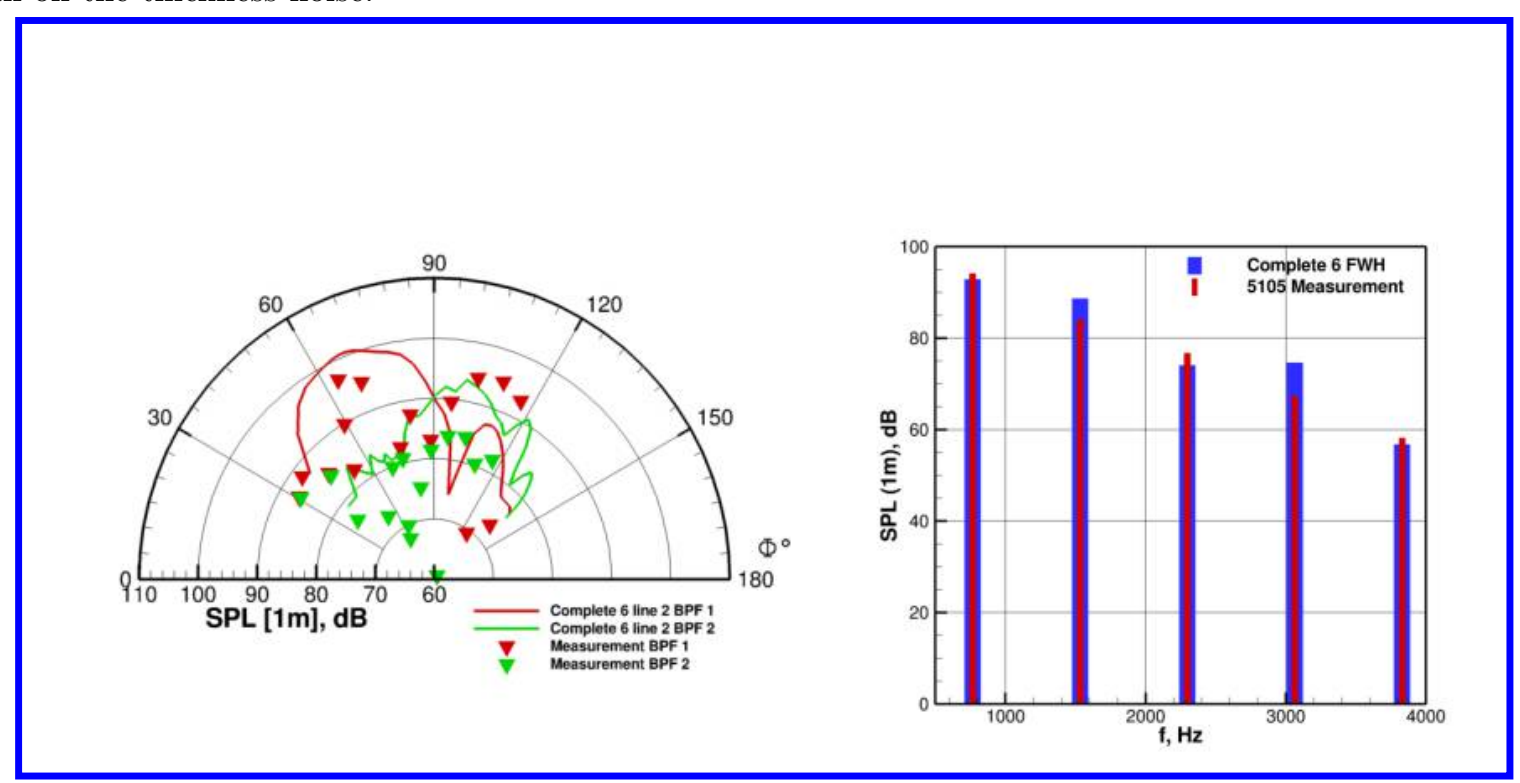

(a) Directivity

(b) Spectra of BPFs for microphone in propeller plane.

Figure 28. Comparison of measured data with computed data microphone $\left(V_{\infty}=51 \mathrm{~m} / \mathrm{s}, \beta=30^{\circ}, \alpha=-5^{\circ}\right.$, $\left.N_{P}=51051 / \min \right)$ 


\section{Summary}

To summarize, an acoustic propeller model is implemented in the CAA-code PIANO. This modeling facilitates a significant reduction in computational time, thus making it usable in the design phase. The model consists of point sources representing the acoustic influence of the propeller blades; monopole sources for thickness noise and dipole sources for loading noise.

Comparison of results on isolated propeller computation (without background flow) with the analytical propeller model shows agreement with respect to the tonal frequencies and decay behavior of the higher harmonic BPFs. The installation effect studies indicate that the ground plate has only a minor effect on the propeller acoustics. The installation effect due to the presence of the high-lift wing increases the sound pressure levels by $5-10 d B$ in most directions. The installation effect is stronger for the loading noise than for the thickness noise, probably caused by an additional sound source due to tip vortices interacting with the geometry. The validation with measurements shows a good agreement. The overall trend of decreased SPL with reduced rotational speed is covered by the model as well as the main parts of the directivity. Furthermore the decay of the SPL for higher harmonics of the BPF is comparable to the measured data. However, the set-up seems to be sensitive to small differences in flow or positions due to occurring interferences. As one of our motivations is to use this prediction tool in the design phase, our future aim is to find the simplest input which still delivers reliable and fairly accurate acoustic predictions. The two main input ingredients are the propeller forces and the background flow. Both would in the ideal case come from 3D uRANS, however, this would also be fairly expensive. To investigate the extent to which expensive CFD is necessary, we have defined several test cases starting from very simple to complex, i.e.,

1. 3D RANS of high-lift wing without propeller and its slipstream

2. 3D RANS of high-lift wing with actuation disk modeling propeller slipstream

3. 3D uRANS of high-lift wing with nacelle and propeller

\section{Acknowledgments}

The work presented in this paper was carried out in the project 'Bürgernahes Flugzeug' which was established in 2009 and is partly funded by the state of Lower Saxony (Germany). Carsten Lenfers (DLR Braunschweig) is kindly acknowledged for providing the RANS background flows and the blade loadings.

\section{References}

\footnotetext{
${ }^{1}$ L. Gutin On the Sound of a Rotating Propeller, NACA TM 1195, 1948.
}

$>^{2}$ R.A.D. Akkermans, M. Pott-Pollenske, H. Buchholz, J.W. Delfs, and D. Almoneit, Installation Effects of a Propeller Mounted on a High-Lift Wing with a Coanda Flap. Part I: Aeroacoustic Experiments, 20th AIAA/CEAS Aeroacoustics Conference, 2014.

${ }^{3}$ M. Lummer, Ch. Richter, C. Pröber, J.W. Delfs, Validation of a Model for Open Rotor Noise Predictions and Calculation of Shielding Effects using a Fast BEM, 19th AIAA/CEAS Aeroacoustics Conference, Berlin, Deutschland, AIAA-2013-2096.

${ }^{4}$ R.A.D. Akkermans, J.W. Delfs, M. Lummer, M. Siefert, B. Caruelle, and C. Tiedemann, Handling of Non-Periodic Contra Rotating Open Rotor Data, 18th AIAA/CEAS Aeroacoustics Conference, AIAA 2012-2262.

${ }^{5}$ R.A.D. Akkermans, A. Stüermer, and J.W. Delfs, Active Flow Control for Interaction Noise Reduction of Contra-Rotating Open Rotors, 49th Joint Propulsion Conference \& Exhibit, AIAA 2013-3799.

${ }^{6}$ J.W. Delfs, M. Bauer, R. Ewert, H.A. Frogger, M. Lummer, T.G.W. Lauke, Numerical Simulations of Aerodynamic Noise with DLRs aeroacoustic code PIANO, PIANO, Vol. handbook version 5.2, 2008.

${ }^{7}$ C. Tam, and J. Webb, Dispersion-Relation-Preserving Finite Difference Schemes for Computational Acoustics, J. Comp. Phys., Vol. 107, pp. 262281, 1993.

${ }^{8}$ F.Q. Hu, M.Y. Hussaini, and J.L. Manthey, Low-dissipation and Low-Dispersion Runge-Kutta Schemes for Computational Acoustics, J. Comp. Phys., Vol. 124, pp. 177-191, 1996.

${ }^{9}$ J.W. Delfs, Aeroakustik, bookchapter in "Handbuch der Luftfahrzeugtechnik" by C-C. Rossow, K. Wolf, P. Horst, Carl Hanser Verlag (2014).

${ }^{10} \mathrm{~J}$. Ffowcs Williams and D. Hawkings, Sound Generation by Turbulence and Surfaces in Arbitrary Motion, Phil. Trans. R. Soc. Lond. Vol. 264, No. 1151, pp. 321-342, 1969.

${ }^{11}$ D.B. Hanson Influence of Propeller Design Parameters on Far Field Harmonic Noise in Forward Flight, AIAA Journal, Vol. 18, No. 11, pp. 1313-1319, 1990.

${ }^{12}$ A. Stüermer and J. Yin, Aerodynamic and Aeroacoustic Installation Effects for Pusher-Configuration CROR Propulsion Systems, 28th AIAA Applied Aerodynamics Conference, AIAA 2010-4235. 
${ }^{13}$ M. Pott-Pollenske, W. von Heesen, and A. Bergmann, Acoustic Preexamination Work and Characterisation of Low Noise Wind Tunnel $D N W / N W B, 18$ th AIAA/CEAS Aeroacoustics Conference (33rd AIAA Aeroacoustics Conference), AIAA 2012-2175.

${ }^{14}$ C. Lenfers, Propeller Design for a future QESTOL Aircraft in the BNF Project, 30th AIAA applied aerodynamics conference, AIAA 2012-3334.

${ }^{15}$ M. Pott-Pollenske, J.W. Delfs, J. Reichenberger, A Testbed for large scale and high Reynolds number Airframe Noise Research, 19th AIAA/CEAS Aeroacoustics Conference, AIAA 2013-2260.

${ }^{16}$ T. Le Garrec, G. Reboul Computational AeroAcoustics of Counter Rotating Open Rotor Model on rear full scale airplane in cruise condition, 18th AIAA/CEAS Aeroacoustics Conference, AIAA 2012-2125.

${ }^{17}$ M. Di Francescantonio, A New Boundary Integral Formulation for the Prediction of Sound Radiation, Journal of Sound and Vibration, Vol. 202(4), pp. 491-509, 1997.

${ }^{18} \mathrm{~K}$. Brentner and F. Farassat An Analytical Comparison of the Acoustic Analogy and Kirchoff Formulation for Moving Surfaces, AIAA Journal, Vol. 36, No. 8, pp. 1379-1386, 1998.

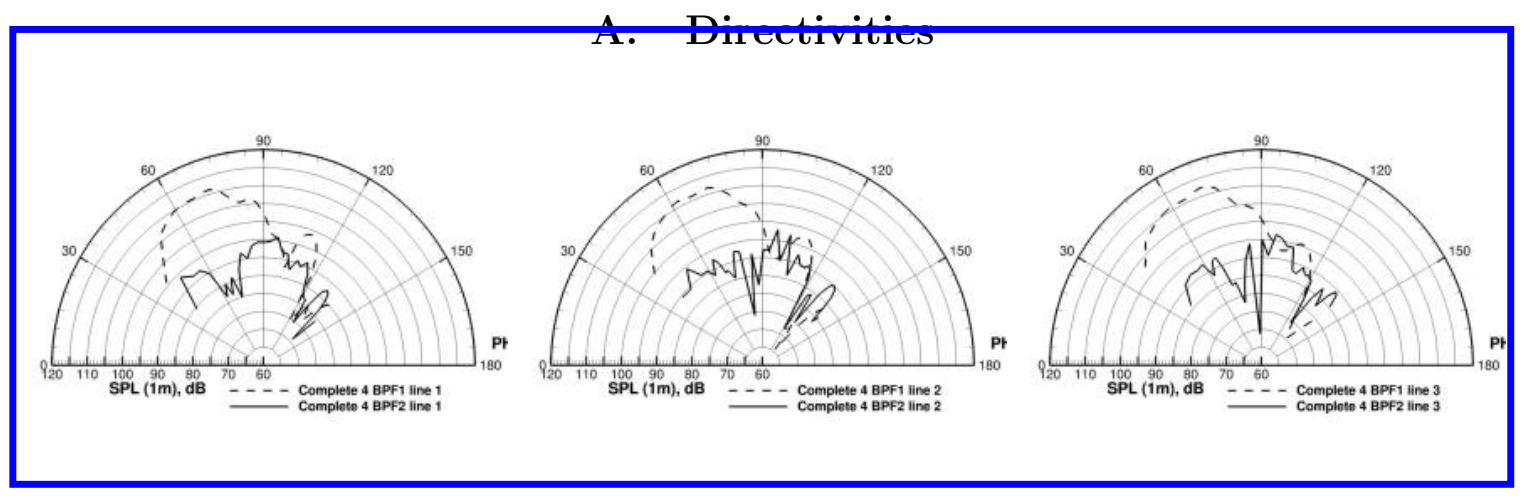

(a) Inboard plane.

(b) Engine plane.

(c) Tip plane.

Figure 29. Directivities for the case $V_{\infty}=51 \mathrm{~m} / \mathrm{s}, \beta=30^{\circ}, \alpha=-5^{\circ}, N_{P}=57431 / \mathrm{min}$.

\section{B. Wall microphone data}

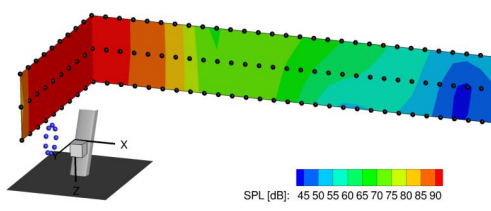

(a) BPF1

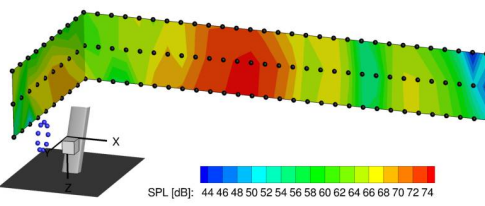

(b) BPF2

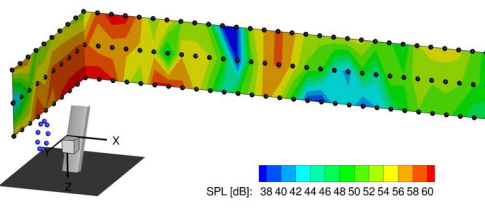

(c) BPF2

Figure 30. Wall microphone data for thickness noise $\left(V_{\infty}=51 \mathrm{~m} / \mathrm{s}, \beta=30^{\circ}, \alpha=-5^{\circ}, N_{P}=57431 / \mathrm{min}\right)$.

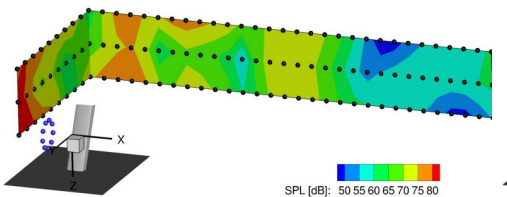

(a) BPF1

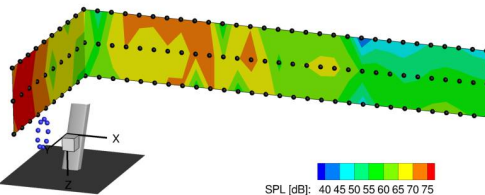

(b) BPF2

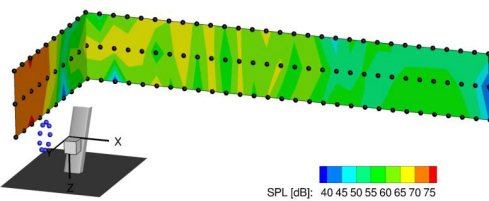

(c) BPF2

Figure 31. Wall microphone data for loading noise $\left(V_{\infty}=51 \mathrm{~m} / \mathrm{s}, \beta=30^{\circ}, \alpha=-5^{\circ}, N_{P}=57431 / \mathrm{min}\right)$. 


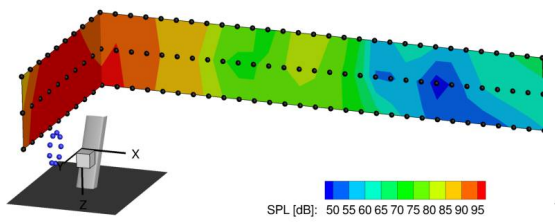

(a) BPF1

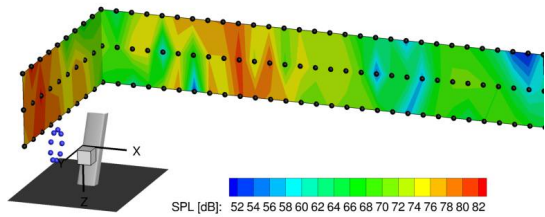

(b) BPF2

Figure 32. Wall microphone data $\left(V_{\infty}=51 \mathrm{~m} / \mathrm{s}, \beta=30^{\circ}, \alpha=-5^{\circ}, N_{P}=57431 / \mathrm{min}\right)$.

\section{Spectra}

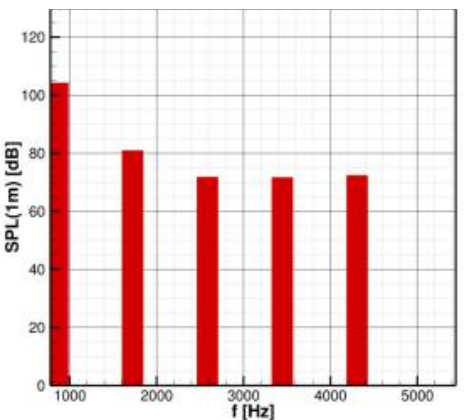

(a) Thickness noise

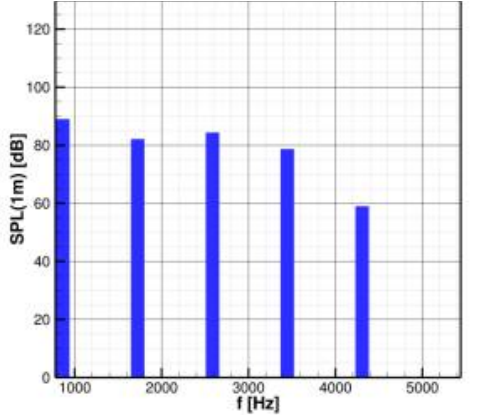

(b) Loading noise

Figure 33. Microphone $0.15 \mathrm{~m}$ in front of the propeller plane $\left(V_{\infty}=51 \mathrm{~m} / \mathrm{s}, \beta=30^{\circ}, \alpha=-5^{\circ}, N_{P}=57431 / \mathrm{min}\right)$

\section{Blade loading}

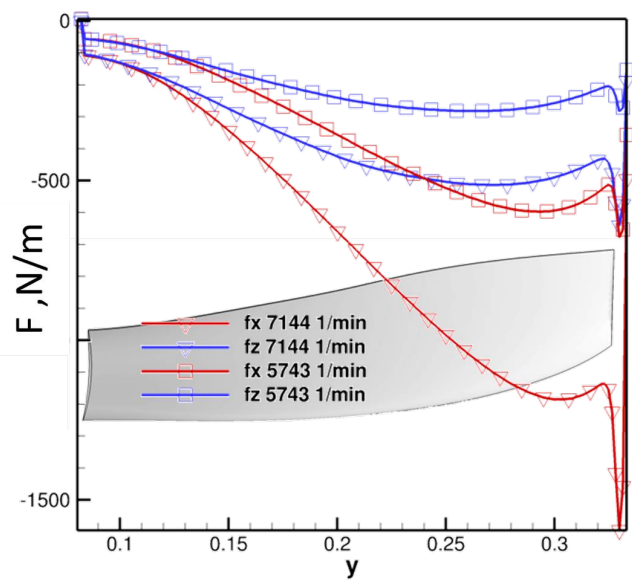

Figure 34. Blade loading over raius $y$. 


\section{E. Installation effect}

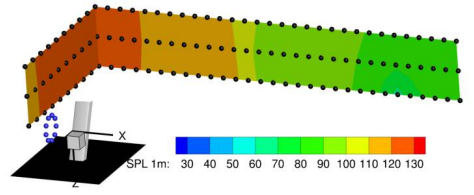

(a) SPL isolated BPF1

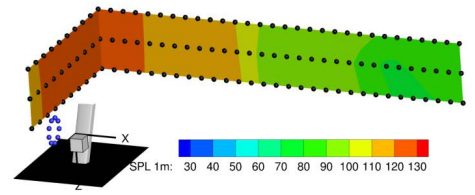

(d) SPL semi installed BPF1

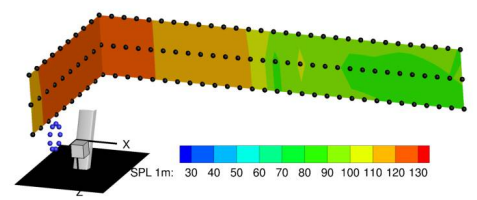

(g) SPL installed BPF1

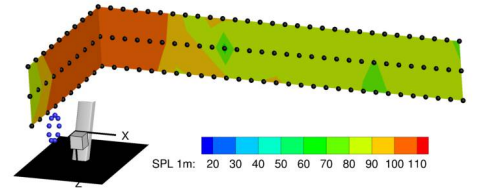

(b) SPL isolated BPF2

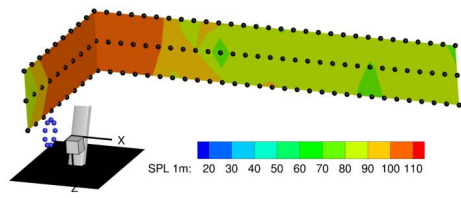

(e) SPL semi installed BPF2

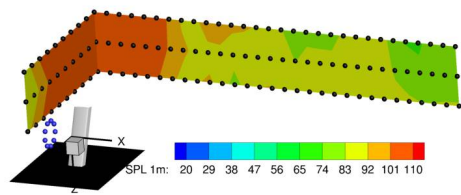

(h) SPL installed BPF2

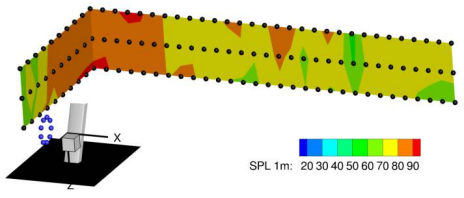

(c) SPL isolated BPF3

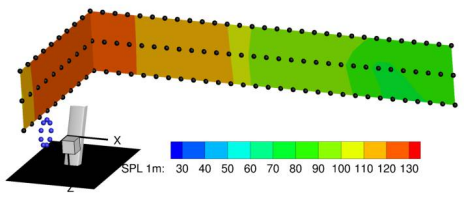

(f) SPL semi installed BPF3

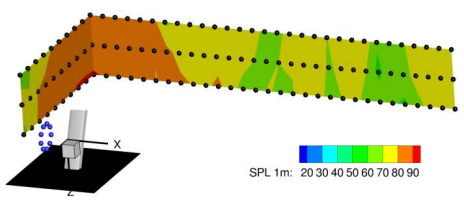

(i) SPL installed BPF3

Figure 35. Wall microphone data for thickness noise $\left(V_{\infty}=51 \mathrm{~m} / \mathrm{s}, \beta=30^{\circ}, \alpha=-5^{\circ}, N_{P}=71441 / \mathrm{min}\right)$.

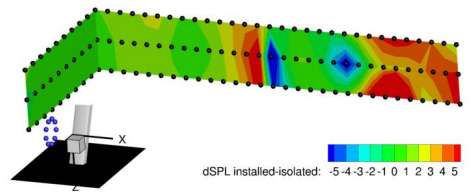

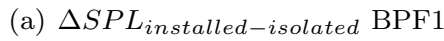

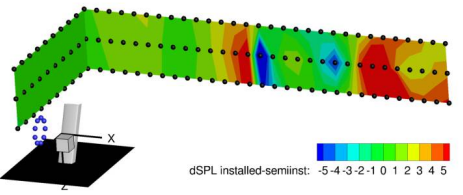

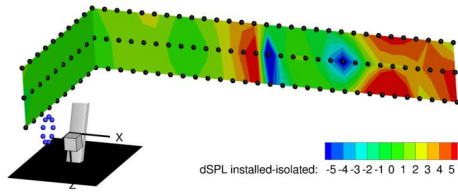

(b) $\triangle S P L_{\text {installed-isolated }} \mathrm{BPF} 2$

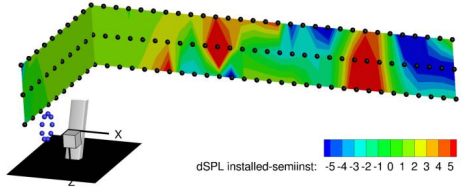

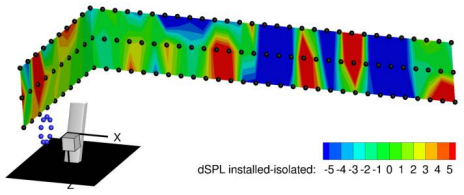

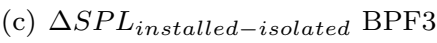

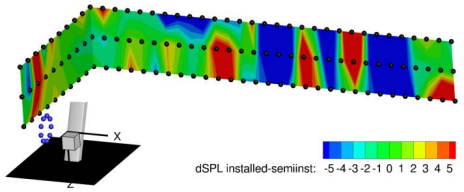

(d) $\triangle S P L_{\text {installed-semiinstalled }}$ BPF1 (e) $\Delta S P L_{\text {installed-semiinstalled }}$ BPF2 (f) $\Delta S P L_{\text {installed-semiinstalled }}$ BPF3
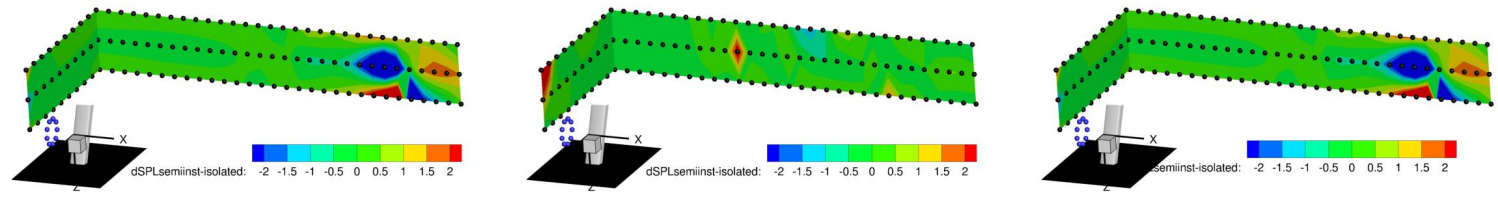

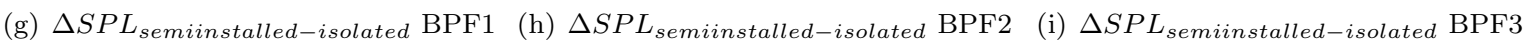

Figure 36. Wall microphone data for thickness noise $\left(V_{\infty}=51 \mathrm{~m} / \mathrm{s}, \beta=30^{\circ}, \alpha=-5^{\circ}, N_{P}=71441 / \mathrm{min}\right)$. 


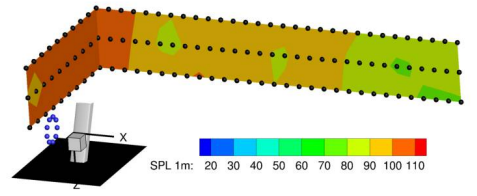

(a) SPL isolated BPF1

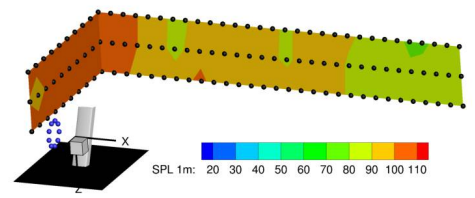

(d) SPL semi installed BPF1

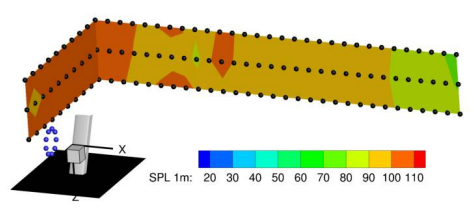

(g) SPL installed BPF1

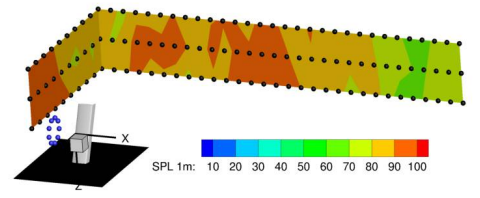

(b) SPL isolated BPF2

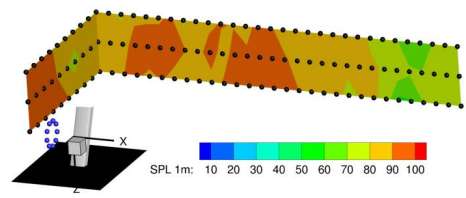

(e) SPL semi installed BPF2

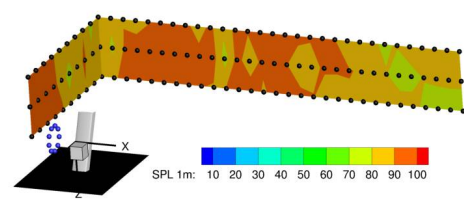

(h) SPL installed BPF2

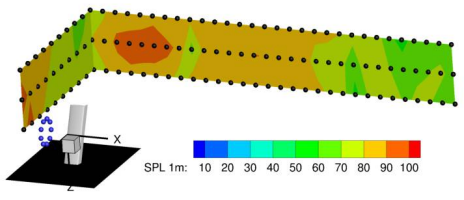

(c) SPL isolated BPF3

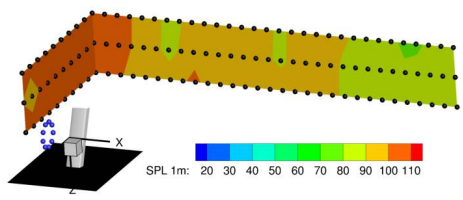

(f) SPL semi installed BPF3

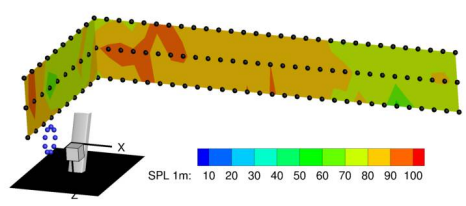

(i) SPL installed BPF3

Figure 37. Wall microphone data for loading noise $\left(V_{\infty}=51 \mathrm{~m} / \mathrm{s}, \beta=30^{\circ}, \alpha=-5^{\circ}, N_{P}=71441 / \mathrm{min}\right)$.

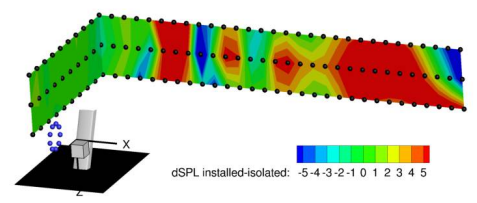

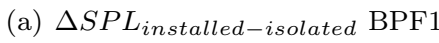

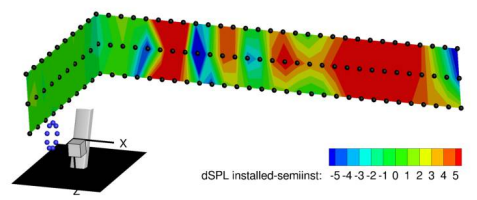

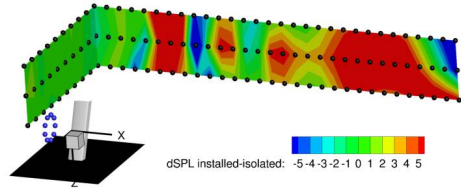

(b) $\triangle S P L_{\text {installed-isolated }} \mathrm{BPF} 2$

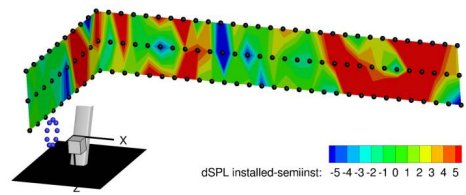

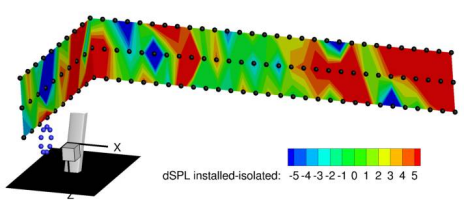

(c) $\triangle S P L_{\text {installed-isolated }}$ BPF3

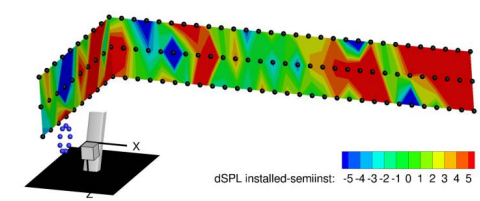

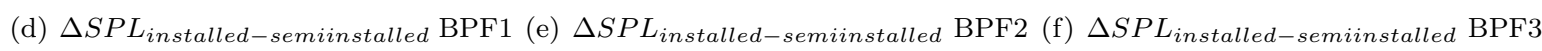
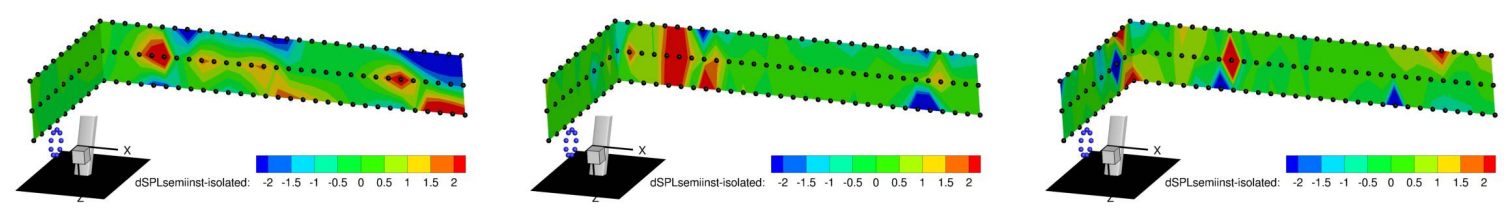

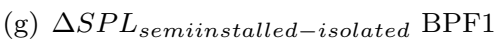

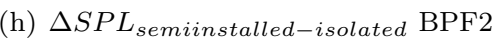

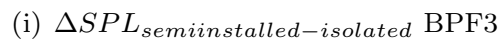

Figure 38. Wall microphone data for loading noise $\left(V_{\infty}=51 \mathrm{~m} / \mathrm{s}, \beta=30^{\circ}, \alpha=-5^{\circ}, N_{P}=71441 / \mathrm{min}\right)$. 
This article has been cited by:

1. Rinie A. Akkermans, Michael Pott-Pollenske, Heino Buchholz, Jan Delfs, Daniela AlmoneitInstallation Effects of a Propeller Mounted on a High-Lift Wing with a Coanda Flap. Part I: Aeroacoustic Experiments . [Citation] [PDF] [PDF Plus] 